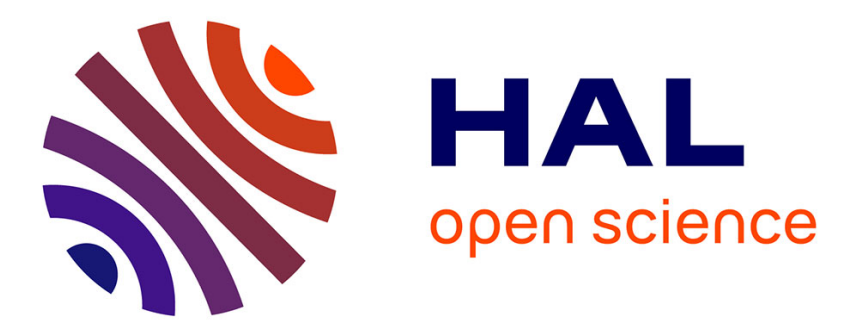

\title{
Three-dimensional transport and concentration of SF 6 A model intercomparison study (TransCom 2)
}

A. Scott Denning, Mark Holzer, Kevin Gurney, Martin Heimann, Rachel Law, Peter Rayner, Inez Fung, Song-Miao Fan, Shoichi Taguchi, Pierre

Friedlingstein, et al.

\section{To cite this version:}

A. Scott Denning, Mark Holzer, Kevin Gurney, Martin Heimann, Rachel Law, et al.. Threedimensional transport and concentration of SF 6 A model intercomparison study (TransCom 2). Tellus B - Chemical and Physical Meteorology, 1999, 51 (2), pp.266-297. 10.3402/tellusb.v51i2.16286 . hal02870565

\section{HAL Id: hal-02870565 \\ https://hal.science/hal-02870565}

Submitted on 29 Oct 2020

HAL is a multi-disciplinary open access archive for the deposit and dissemination of scientific research documents, whether they are published or not. The documents may come from teaching and research institutions in France or abroad, or from public or private research centers.
L'archive ouverte pluridisciplinaire HAL, est destinée au dépôt et à la diffusion de documents scientifiques de niveau recherche, publiés ou non, émanant des établissements d'enseignement et de recherche français ou étrangers, des laboratoires publics ou privés. 


\section{Three-dimensional transport and concentration of $\mathrm{SF}_{6} \mathrm{~A}$ model intercomparison study (TransCom 2)}

\section{A. Scott Denning, Mark Holzer, Kevin R. Gurney, Martin Heimann, Rachel M. Law, Peter J. Rayner, Inez Y. Fung, Song-Miao Fan, Shoichi Taguchi, Pierre Friedlingstein, Yves Balkanski, John Taylor, Manfred Maiss \& Ingeborg Levin}

To cite this article: A. Scott Denning, Mark Holzer, Kevin R. Gurney, Martin Heimann, Rachel M. Law, Peter J. Rayner, Inez Y. Fung, Song-Miao Fan, Shoichi Taguchi, Pierre Friedlingstein, Yves Balkanski, John Taylor, Manfred Maiss \& Ingeborg Levin (1999) Three-dimensional transport and concentration of $\mathrm{SF}_{6} \mathrm{~A}$ model intercomparison study (TransCom 2), Tellus B: Chemical and Physical Meteorology, 51:2, 266-297, DOI: 10.3402/tellusb.v51i2.16286

To link to this article: https://doi.org/10.3402/tellusb.v51i2.16286

$$
\begin{aligned}
& \text { (c) } 1999 \text { The Author(s). Published by Taylor \& } \text { Francis. } \\
& \text { Published online: } 15 \text { Dec } 2016 .
\end{aligned}
$$

Submit your article to this journal $\longleftarrow \quad$ আll Article views: 196 


\title{
Three-dimensional transport and concentration of $\mathrm{SF}_{6}$ A model intercomparison study (TransCom 2)
}

\author{
By A. SCOTT DENNING ${ }^{1, *}$, MARK HOLZER ${ }^{2}$, KEVIN R. GURNEY $^{1}$, MARTIN HEIMANN $^{3}$, \\ RACHEL M. LAW ${ }^{4}$, PETER J. RAYNER ${ }^{4}$, INEZ Y. FUNG ${ }^{5,6}$, SONG-MIAO FAN ${ }^{7}$, SHOICHI \\ TAGUCHI $^{8}$, PIERRE FRIEDLINGSTEIN ${ }^{5}$, YVES BALKANSKI ${ }^{9}$, JOHN TAYLOR $^{10}$, MANFRED \\ MAISS $^{11}$, and INGEBORG LEVIN ${ }^{12}{ }^{1}$ Department of Atmospheric Science, Colorado State University, \\ Fort Collins, CO 80523-1371, USA ${ }^{2}$ Canadian Center for Climate Modeling and Analysis, Atmospheric \\ Environment Service, University of Victoria, Victoria, B.C., Canada V8W 2Y2; ${ }^{3}$ Max-Planck-Institut für \\ Meteorologie, Bundesstrasse 55, D-2000 Hamburg 13, Germany; ${ }^{4}$ CRC for Southern Hemisphere \\ Meteorology, Monash University, Clayton, Victoria 3168, Australia; ${ }^{5}$ NASA Goddard Institute for Space \\ Studies, New York, NY, USA; ${ }^{6}$ Center for Atmospheric Sciences, McCone Hall, University of California, \\ Berkeley, CA, USA $;{ }^{7}$ Atmospheric and Oceanic Sciences, Sayre Hall, Princeton University, Princeton, NJ, \\ USA; ${ }^{8}$ National Institute for Resources and Environment, 16-3, Onagawa Tsukuba, Ibaraki, Japan; ${ }^{9}$ Centre \\ des Faibles Radioactivites, LMCE, Gif-sur-Yvette, Saclay, France; ${ }^{10}$ Centre for Resource and \\ Environmental Studies, Australia National University, Canberra, ACT 0200, Australia; ${ }^{11}$ Max-Planck- \\ Institute for Chemistry, Air Chemistry Division, Mainz, Germany; ${ }^{12}$ Institut für Umweltphysik, University \\ of Heidelberg, Heidelberg, Germany
}

(Manuscript received 5 December 1997; in final form 22 October 1998)

\section{ABSTRACT}

Sulfur hexafluoride $\left(\mathrm{SF}_{6}\right)$ is an excellent tracer of large-scale atmospheric transport, because it has slowly increasing sources mostly confined to northern midlatitudes, and has a lifetime of thousands of years. We have simulated the emissions, transport, and concentration of $\mathrm{SF}_{6}$ for a 5-year period, and compared the results with atmospheric observations. In addition, we have performed an intercomparison of interhemispheric transport among 11 models to investigate the reasons for the differences among the simulations. Most of the models are reasonably successful at simulating the observed meridional gradient of $\mathrm{SF}_{6}$ in the remote marine boundary layer, though there is less agreement at continental sites. Models that compare well to observations in the remote marine boundary layer tend to systematically overestimate $\mathrm{SF}_{6}$ at continental locations in source regions, suggesting that vertical trapping rather than meridional transport may be a dominant control on the simulated meridional gradient. The vertical structure of simulated $\mathrm{SF}_{6}$ in the models supports this interpretation. Some of the models perform quite well in terms of the simulated seasonal cycle at remote locations, while others do not. Interhemispheric exchange time varies by a factor of 2 when estimated from 1-dimensional meridional profiles at the surface, as has been done for observations. The agreement among models is better when the global surface mean mole fraction is used, and better still when the full 3-dimensional mean mixing ratio is used. The ranking of the interhemispheric exchange time among the models is not sensitive to the change from station values to surface means, but is very sensitive to the change from surface means to the full 3-dimensional tracer fields. This strengthens the argument that vertical redistribution dominates over interhemispheric transport in determining the meridional gradient at the surface. Vertically integrated meridional transport in the models is divided roughly equally into transport by the mean motion, the standing eddies, and the transient eddies. The vertically integrated mass flux is a good index of the degree to

* Corresponding author. 
which resolved advection vs. parameterized diffusion accomplishes the meridional transport of $\mathrm{SF}_{6}$. Observational programs could provide a much better constraint on simulated chemical tracer transport if they included regular sampling of vertical profiles of nonreactive trace gases over source regions and meridional profiles in the middle to upper troposphere. Further analysis of the $\mathrm{SF}_{6}$ simulations will focus on the subgrid-scale parameterized transports.

\section{Introduction}

The large-scale spatial and temporal distribution of observed atmospheric $\mathrm{CO}_{2}$ concentration contains information about the configuration and magnitude of its surface sources and sinks. This information can be extracted by inversion methods using chemical tracer transport models (CTMs) (Fung et al., 1983; Heimann and Keeling, 1989; Tans et al., 1990; Enting et al., 1995; Ciais et al., 1995). An important source of uncertainty in such inversion calculations is the simulated transport itself, which varies among the many models used.

To characterize this uncertainty, the Atmospheric Tracer Transport Model Intercomparison Project (TransCom) was initiated following discussions at the 4th International $\mathrm{CO}_{2}$ Conference. Thus far, the TransCom community has reported on fossil-fuel $\mathrm{CO}_{2}$ and seasonal vegetation experiments (Rayner and Law, 1995; Law et al., 1996). Here we report on the second phase of TransCom, in which we carry out a new intercomparison of model simulations of sulfur hexafluoride transport.

The $\mathrm{CO}_{2}$ inversion approach relies on the correct simulation of the relationship between emissions of $\mathrm{CO}_{2}$ (primarily in the northern hemisphere midlatitudes) and the resulting $\mathrm{CO}_{2}$ concentration at observing sites (primarily in the remote marine boundary layer, MBL). The simulated spatial distribution is validated against measurements from the $\mathrm{CO}_{2}$ flask network. Analysis of the TransCom 1 simulations indicated large differences among models in the simulated distribution of the two $\mathrm{CO}_{2}$ tracers considered (the fossil-fuel component and the annually balanced biotic component), particularly in terms of the meridional structure of $\mathrm{CO}_{2}$. Conclusions from TransCom 1 were limited because the simulations did not include the full carbon budget, so that simulated concentrations could not easily be compared to observations. Hence, the TransCom 1 participants and interested contributors agreed to perform a new experiment with a tracer that could be compared to atmospheric data at many locations, so that errors in the simulated transport could be identified.

For this new experiment, we sought a long-lived tracer with steady anthropogenic emissions analogous to $\mathrm{CO}_{2}$, abundant observational data, and no interaction with biological processes. A tracer that satisfies these criteria is sulfur hexafluoride $\left(\mathrm{SF}_{6}\right)$. Meridional transport of anthropogenic tracers in CTMs has been investigated using chlorofluorocarbons (CFCs) (Prather et al., 1987; Hartley et al., 1994; Pyle and Prather, 1996) and Krypton-85 (Jacob et al., 1987; Heimann and Keeling, 1989). Since the adoption of international agreements to phase out production of CFCs, emissions have been falling rapidly (WMO, 1995), complicating their use as calibration tracers. Vertical tracer transport has been investigated through simulations of the short-lived radioisotope Radon-222 (Heimann and Keeling, 1989; Feichter and Crutzen, 1990; Mahowald et al., 1995; Jacob et al., 1997), but we chose to focus on meridional distributions and interhemispheric transport of long-lived tracers for the present experiment.

Sulfur hexafluoride is an anthropogenic trace gas with an atmospheric lifetime of over 3000 years (Ravishankara et al., 1993), whose mixing ratio is increasing rapidly in the troposphere (Maiss and Levin, 1994; Levin and Hesshaimer, 1996; Maiss et al, 1996; Geller et al., 1997). It is believed to be emitted by slow leakage primarily from electrical switching equipment. Unlike other anthropogenic tracers such as CFCs and krypton- $85, \mathrm{SF}_{6}$ has comparatively steady emissions growth, so that the relative spatial distribution, well-characterized at the surface by sampling programs, is nearly constant. The global source has been estimated from its concentration time series at various locations (Maiss et al., 1996). 
This paper presents initial results from phase 2 of the TransCom project, in which eleven 3-dimensional tracer models were used to simulate the distribution of $\mathrm{SF}_{6}$. This study has three objectives: (1) to compare model simulations to one another and to available observational data; (2) to investigate mechanisms by which the models produce different or unrealistic results; and (3) to suggest high-priority areas of improvement for both model development and observational programs, with the aim of strengthening the observational constraints on tracer transport. The focus in this paper is on a comparison of the simulations to available observations and on an intercomparison of the resolved transport by advection. A subsequent paper will analyze the simulated transport by parameterized subgrid-scale processes.

\section{Experimental method}

Emissions of $\mathrm{SF}_{6}$ were prescribed according to the global estimates of Levin and Hesshaimer (1996). These estimates were linearly interpolated to daily values defined on the 15 th of each month between December 1988 and January 1994. The global emissions were distributed geographically on a $0.5^{\circ} \times 0.5^{\circ}$ grid (Fig. 1), according to electrical power usage by country (UN Energy Statistics Yearbook, 1992) and population density (Tobler, 1995). This distribution attempts to cap-

\section{$\log _{10}\left(\mathrm{pg} \mathrm{m}^{-2} \mathrm{~s}^{-1}\right)$}

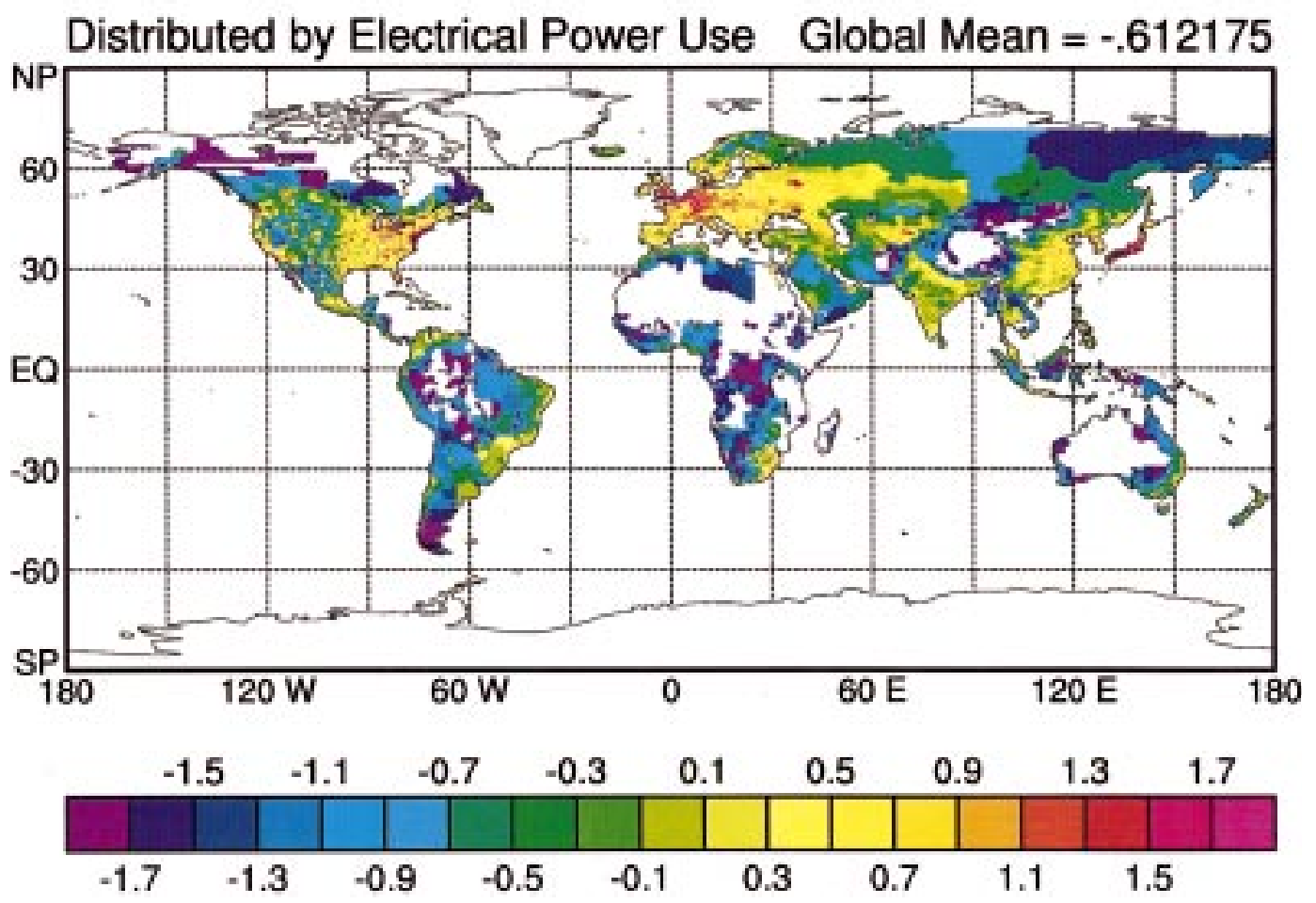

Fig. 1. Estimated $\mathrm{SF}_{6}$ emissions for 1992. The global $\mathrm{SF}_{6}$ emission rate is derived from a $2 \mathrm{D}$ tracer transport model constrained by surface $\mathrm{SF}_{6}$ observations (Levin and Hesshaimer, 1996). The global emissions were distributed by country according to electrical power usage (UN Energy Statistics Yearbook, 1992). Within individual countries, emissions were distributed by population density ( $5^{\prime}$ population map of CIESIN, Tobler et al, 1995) onto a $0.5^{\circ}$ $($ lat $\times$ lon) grid. The resulting emissions were then averaged to participant model grids. 
ture the predominant source of $\mathrm{SF}_{6}$ to the troposphere due to leakage from electrical switching equipment. Each participating group then computed the area-weighted average of the emissions distribution onto their (coarser) model grid, and scaled the values to preserve the global integral.

Eleven modeling groups have submitted results for the $\mathrm{SF}_{6}$ experiment to date, including most of the participants in the TransCom 1 intercomparison as well as several additional models (Table 1). A brief description of each model is provided in Section 7.

Several of the TransCom 1 participants did not submit results for TransCom 2 (CSIRO9, MUGCM, TM1). In addition, some of the models being compared in the present paper have been modified since the earlier TransCom 1 experiments, or were run at higher resolution (ANU, CSU, GISS, NIRE), and several new models have been added (CCC, GFDL-SKYHI, GISS-UVic, TM3). Only three of the models in the present intercomparison use codes identical to those used in TransCom 1 (GFDL-GCTM, MUTM, and TM2).

The models were initialized on January 1, 1989 with a globally uniform $\mathrm{SF}_{6}$ concentration of 2.06 parts per trillion by volume (pptv) (Maiss et al., 1996). Each model was then integrated for 5 years, updating the emissions field continuously, ending on 31 December, 1993. Simulated tracer statistics and diagnostic output were archived for the final 12 months of the integration.

The model output was designed to compare the simulated $\mathrm{SF}_{6}$ mixing ratio to observational data, and to elucidate the mechanisms responsible for the differences among simulations. Output was reported for both resolved advective transport and subgrid-scale parameterized transport. To allow for the construction of budgets and the quantitative comparison of various budget components, transport diagnostics were interpolated to pressure coordinates and vertically integrated over three slabs subdividing the troposphere. Resolved advection was calculated in terms of mass fluxes, and subgrid-scale parameterized transport, in terms of tendencies. Mass fluxes were calculated from "local anomaly" mixing ratios $\left(C^{+} \equiv C-C_{0}\right)$ after subtracting the global mean (background) mixing ratio of $\mathrm{SF}_{6}\left(C_{0}\right)$, to provide a more robust estimate of the advective transport.

Observational data used to evaluate model per- formance were gathered from a number of sources representing various time periods and frequencies (Fig. 2). Many of the observational data have become available since the experimental protocol was developed. The rapid accumulation rate of $\mathrm{SF}_{6}$ in the troposphere precludes the direct comparison of newer data to the model simulations for 1993. To allow for comparison to model output, data collected in other years were therefore extrapolated to the intercomparison year using a linear trend of $0.202 \mathrm{pptv} \mathrm{yr}^{-1}$ derived from the data (reflecting a mid-1990s growth rate). This trend is slightly less than the earlier trend of 0.225 reported by Maiss et al. (1996), and is based on analysis of many more stations.

\section{Simulated tracer distributions: comparison with observations}

\subsection{Surface tracer distribution}

Initial comparisons (not shown) demonstrated that the simulated surface mole fraction was higher than observed for every model at all times of the year at most of the sites active in 1993. We interpret this universal overestimate to mean that either (1) our global emissions estimates were too large; or (2) our initial condition of 2.06 pptv was too high. Surprisingly, these same global emission rates produced successful simulations in the 2-dimensional model of Levin and Hesshaimer (1996). A probable explanation is that longitudinal and vertical variations are not well-observed and in general, are not well captured in 2D models compared to 3D models. The initial condition was chosen based on the global mean mole fraction estimated from surface observations at a handful of stations (Maiss et al., 1996), and assumed to pertain to the entire mass of the atmosphere, which certainly overestimates the mass of $\mathrm{SF}_{6}$ aloft.

We adjusted the simulated mole fraction by scaling the mole fraction difference from the initial condition of $2.06 \mathrm{pptv}$, to correct for this apparent overestimate of the global $\mathrm{SF}_{6}$ emissions rate. The scale factor was obtained by minimizing the difference between simulated and observed mole fractions at those stations with measurements for each month of 1993 (Neumayer, Cape Grim, Izaña, and Alert). Therefore, all simulated mole fractions presented herein have been adjusted 
Table 1. Characteristics of the participating models

\begin{tabular}{|c|c|c|c|c|c|c|c|c|c|c|c|c|}
\hline \multirow[b]{2}{*}{ Model } & \multirow[b]{2}{*}{ Contact } & \multirow[b]{2}{*}{ Type } & \multirow[b]{2}{*}{ Reference } & \multirow[b]{2}{*}{$\begin{array}{l}\text { Horizontal } \\
\text { grid }\end{array}$} & \multirow[b]{2}{*}{ \# Levels } & \multirow[b]{2}{*}{ Advection } & \multirow[b]{2}{*}{ Wind } & \multirow[b]{2}{*}{ Freq. } & \multicolumn{4}{|c|}{ Parameterized transport } \\
\hline & & & & & & & & & $\begin{array}{c}\mathrm{H} \\
\text { diff. }\end{array}$ & $\begin{array}{c}\mathrm{V} \\
\text { diff. }\end{array}$ & Conv. & $\begin{array}{c}\text { Explici } \\
\text { PBL }\end{array}$ \\
\hline ANU & Taylor & CTM & Taylor, 1989 & $2.5^{\circ}$ & 15 pressure & Langrangian & ECMWI (88-93) & $6 \mathrm{~h}$ & $\mathrm{Y}$ & Y & $\mathrm{C}$ & $\mathrm{Y}$ \\
\hline $\mathrm{CCC}$ & Holzer & GCM & $\begin{array}{l}\text { McFarlane } \\
\text { et al. (1992) }\end{array}$ & $3.75^{\circ}$ & $10 \sigma /$ pres. & spectral & on-line & - & $\mathrm{Y}$ & Y & B & $\mathrm{N}$ \\
\hline CSU & Denning & GCM & $\begin{array}{l}\text { Denning et al. } \\
\text { (1996) }\end{array}$ & $4^{\circ} \times 5^{\circ}$ & $17 \sigma$ & 2nd order & on-line & - & $\mathrm{N}$ & $\mathrm{N}$ & $\mathrm{C}$ & $\mathrm{Y}$ \\
\hline $\begin{array}{l}\text { GFDL- } \\
\text { GCTM }\end{array}$ & Fan & CTM & $\begin{array}{l}\text { Mahlman and } \\
\text { Moxim (1978) }\end{array}$ & $\begin{array}{c}256 \mathrm{~km} \\
11 \sigma\end{array}$ & 2 nd order & GFDL ZODIAC & $6 \mathrm{~h}$ & $\mathrm{Y}$ & $\mathrm{Y}$ & A & $\mathrm{N}$ & \\
\hline $\begin{array}{l}\text { GFDL- } \\
\text { SKYHI }\end{array}$ & Fan & GCM & $\begin{array}{l}\text { Hamilton et al. } \\
\qquad(1995)\end{array}$ & $3^{\circ} \times 3.6^{\circ}$ & $40 \sigma$ & $\begin{array}{l}\text { 2nd order (horiz.) } \\
\text { 4th (vertical) }\end{array}$ & on-line & - & $\mathrm{Y}$ & Y & A & $\mathrm{N}$ \\
\hline GISS & Fung & CTM & $\begin{array}{c}\text { Hansen et al. } \\
\text { (1984) }\end{array}$ & $4^{\circ} \times 5^{\circ}$ & $9 \sigma$ & slope & GISS CGM II & $4 \mathrm{~h}$ & $\mathrm{Y}$ & $\mathrm{N}$ & B & $\mathrm{N}$ \\
\hline $\begin{array}{l}\text { GISS- } \\
\text { UVic }\end{array}$ & $\begin{array}{c}\text { Fung/ } \\
\text { Friedlingstein }\end{array}$ & CTM & $\begin{array}{l}\text { Hansen et al. } \\
\text { (1997) }\end{array}$ & $4^{\circ} \times 5^{\circ}$ & $9 \sigma$ & slope & GISS GCM II' & $1 \mathrm{~h}$ & $\mathrm{~N}$ & $\mathrm{~N}$ & $\mathrm{C}$ & $\mathrm{N}$ \\
\hline MUTM & Law & CTM & $\begin{array}{c}\text { Law et al. } \\
\text { (1992) }\end{array}$ & $3.33^{\circ} \times 5.63^{\circ}$ & $9 \sigma$ & spectral & MU GCM 7 & $24 \mathrm{~h}$ & $\mathrm{Y}$ & $\mathrm{Y}$ & B & $\mathrm{N}$ \\
\hline NIRE & Taguchi & CTM & Taguchi (1996) & $2.5^{\circ}$ & $15 \sigma /$ pres. & semi-Langrangian & ECMWF(93) & $6 \mathrm{~h}$ & $\mathrm{~N}$ & $\mathrm{~N}$ & $\mathrm{~N}$ & $\mathrm{Y}$ \\
\hline $\mathrm{TM} 2$ & $\begin{array}{l}\text { Balanski/ } \\
\text { Bousquet }\end{array}$ & CTM & $\begin{array}{c}\text { Bousquet et al. } \\
\text { (1996) }\end{array}$ & $7.5^{\circ}$ & $9 \sigma$ & slope & ECMWF(93) & $12 \mathrm{~h}$ & $\mathrm{~N}$ & Y & $\mathrm{C}$ & $\mathrm{N}$ \\
\hline TM3 & Heimann & CTM & Heimann (1995) & $3.75^{\circ} \times 5^{\circ}$ & $19 \sigma$ & slope & ЕСНАM3 GCM & $6 \mathrm{~h}$ & $\mathrm{~N}$ & $\mathrm{Y}$ & $\mathrm{C}$ & $\mathrm{N}$ \\
\hline
\end{tabular}

The convection schemes generally fell into one of three categories: (A) simple diffusion, (B) pairwise layer mixing, (C) penetrative mass flux. "On-line" models, (CCC, CSU, and GFDL-SKYHI) simulate tracer transport in a fully prognostic general circulation model (GCM), calculating winds and subgrid-scale transport on time steps of minutes. "Off-line" models (CTMs) calculate tracer transport from either analyzed winds (ANU, NIRE, TM2) or GCM output (GFDL-GCTM, GISS, GISS-UVic, MUTM, TM3). The off-line models are able to use much longer time steps, and specify input wind fields with frequencies varying from $1 \mathrm{~h}$ to 1 day. Subgrid-scale vertical transport was parameterized in all models, using a variety of techniques. Off-line models generally include schemes to calculate these terms from the prescribed wind input, whereas on-line models calculate subgrid-scale transports at the same time as the dynamical calculation of the GCM winds. GCM calculations used on-line winds calculated using climatological sea-surface temperatures as a lower boundary condition. For additional details please refer to Section 7. 

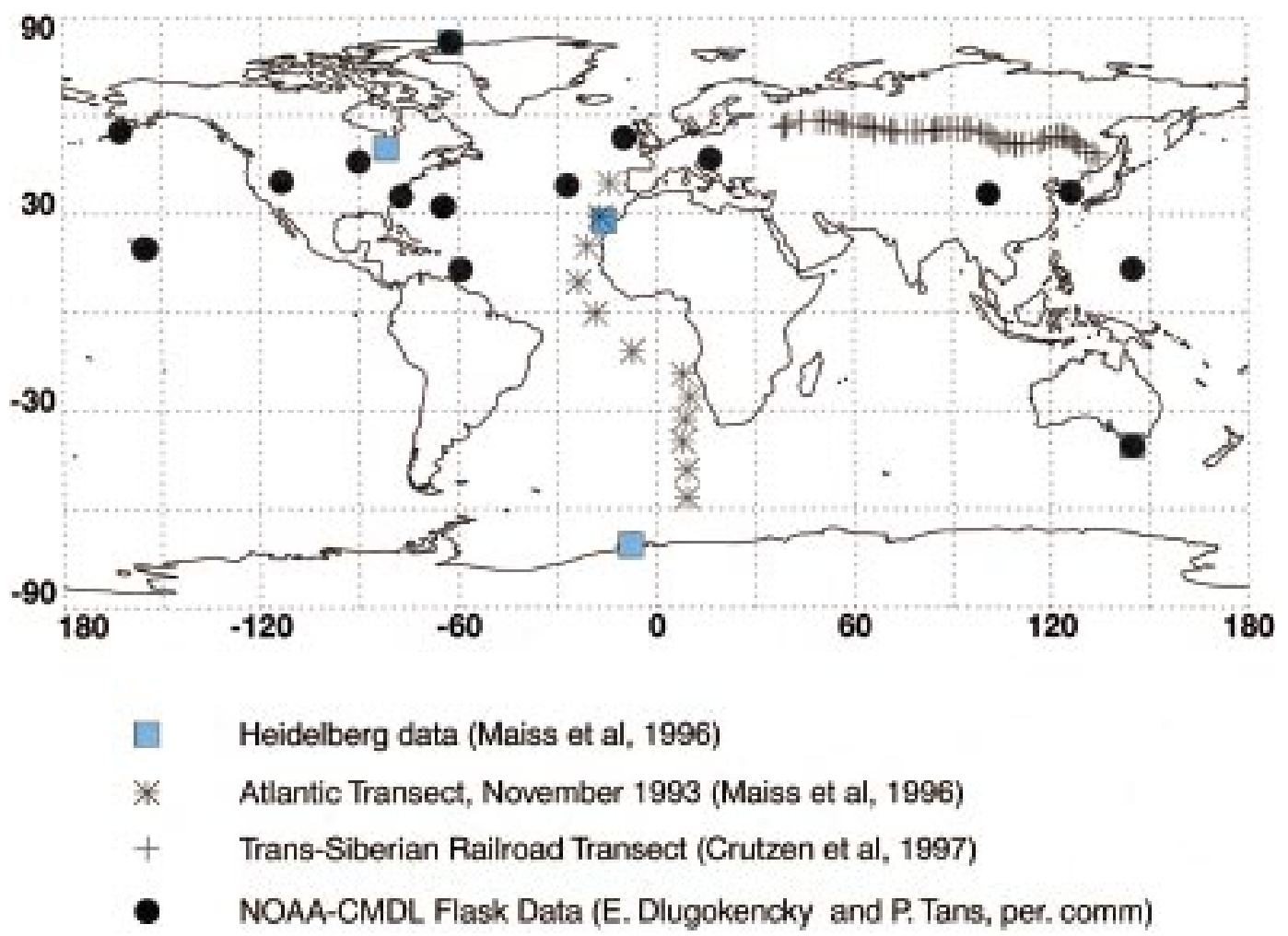

Fig. 2. Locations of observed $\mathrm{SF}_{6}$ mole fractions used for comparison to model simulations. Asterisks denote measurements taken during a ship cruise in the Atlantic Ocean during October/November, 1993 (Maiss et al., 1996; Levin and Hesshaimer, 1996). Plus symbols denote $\mathrm{SF}_{6}$ measurements taken during two Trans-Siberian Railroad transects across Eurasia from Moscow to Vladivostok during July/August, 1996 (Crutzen et al., 1998). Squares denote measurements taken at 5 stations representing the remote troposphere at latitudes from $83^{\circ} \mathrm{N}$ to the Antarctic coast over time periods ranging from 1 to 25 years (Maiss et al., 1996; Levin and Hesshamier, 1996). Circles denote the NOAACMDL flask data analyzed for $\mathrm{SF}_{6}$ since late 1995 (E. Dlugokencky and P. Tans, personal communication). Included with the NOAA-CMDL data are 2 hourly time series of $\mathrm{SF}_{6}$ measured near the top of tall television towers in North Carolina (WITN-TV) and Wisconsin, USA (WLEF-TV) since 1994 (Hurst et al., 1997).

downward according to

$\chi_{\text {adj }}=2.06+0.936(\chi-2.06)$ pptv.

This adjustment is consistent with our initialization and is supported by a recent reanalysis of the $\mathrm{SF}_{6}$ time series (Manfred Maiss, personal communication) which produced emissions estimates that are about $3-4 \%$ lower than those of Levin and Hesshaimer (1996).

Simulated mole fractions in the remote MBL display a pole-to-pole difference of about $10 \%$ ( 0.3 pptv) (Fig. 3, Table 2). Most of the models capture the observed magnitude of this meridional gradient, with considerably less model-to-model variance than for TransCom 1 (Law et al., 1996). This may be due to improvements in some of the models since the earlier experiment. In addition, the CSIRO9 model, which produced strong gradients in surface concentration, was not included in TransCom 2. Furthermore, less variation is expected for "clean air" sites in the remote MBL than for the surface zonal means that were compared in TransCom 1.

Maps of the simulated annual mean $\mathrm{SF}_{6}$ surface mole fraction and its deviation from observed values (Fig. 4) show that some models (CCC, GFDL-GCTM, GFDL-SKYHI, NIRE, and TM3) exhibit much higher concentrations in the vicinity 


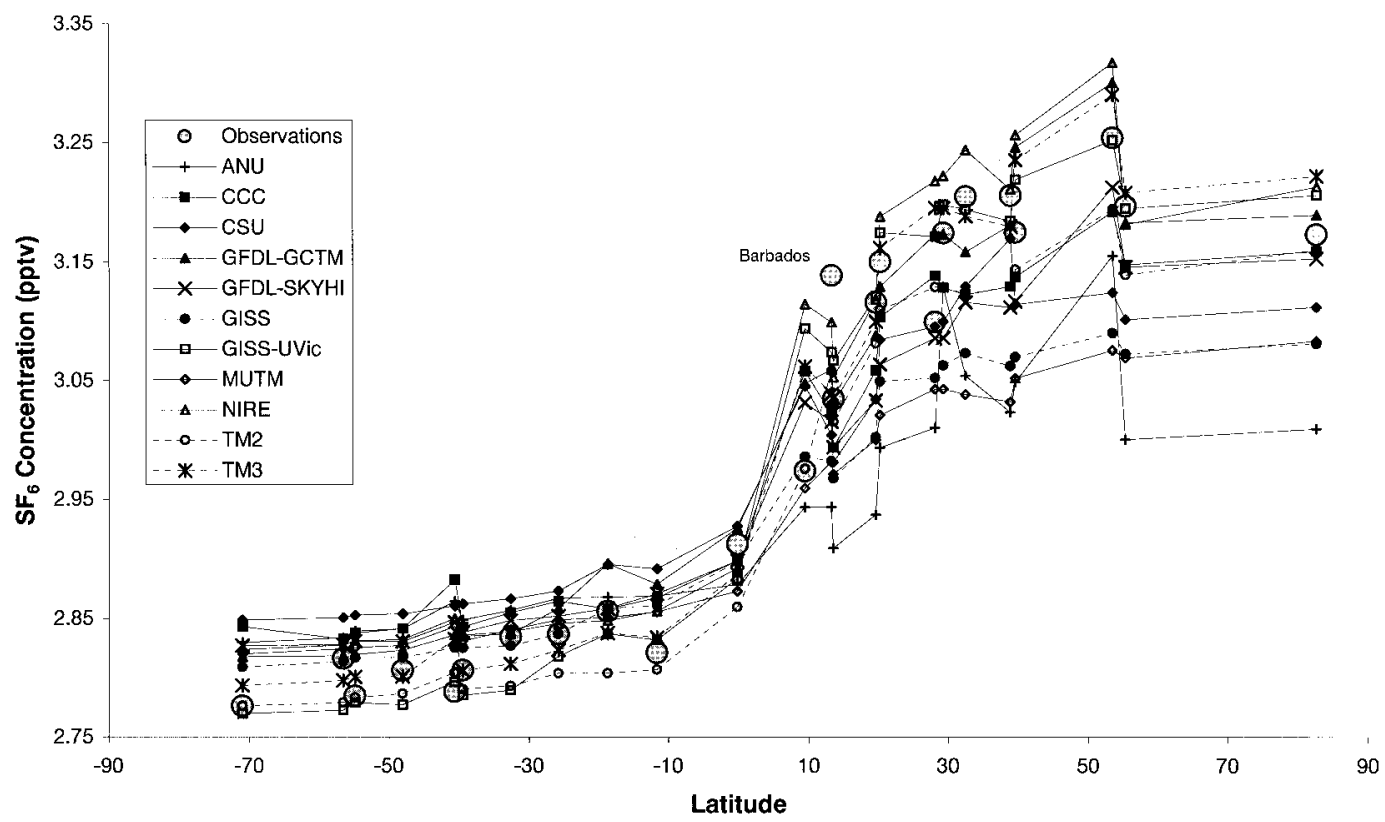

Fig. 3. Meridional profiles of simulated and observed 1993 annual mean surface mole fraction of $\mathrm{SF}_{6}$. Observed data include all October/November 1993 Atlantic transect measurements, station locations considered within the marine boundary layer, and Izaña, which is in the mid-troposphere. The observations were extrapolated in time using a linear trend of $0.202 \mathrm{pptv} / \mathrm{yr}$ derived from the data for the mid-1990s. This value reflects the average growth rate at the measurement stations.

of emission maxima than the remaining models (CSU, GISS, MUTM, and TM2). The ANU and GISS-UVic models are intermediate between these extremes. Some of the models that are most successful in reproducing the meridional gradient in the remote MBL overestimate the mole fraction in the source regions (GCTM, TM3, and to a lesser extent CCC). The ANU model simulates moderately high mixing ratios in the source regions, but exhibits the lowest mixing ratios elsewhere in the northern hemisphere. The ANU, CSU, GISS, MUTM, and TM2 models underestimate $\mathrm{SF}_{6}$ throughout the Northern Hemisphere, and the NIRE model overestimates $\mathrm{SF}_{6}$ almost everywhere.

There is some indication that the maximum surface mixing ratio simulated in the source regions depends on the horizontal resolution of the models (compare Fig. 4 and Table 1). This would be expected since the prescribed emissions field (Fig. 1) exhibits local extrema that would be smeared out on the coarser model grids. This might explain the very strong concentration maxima in the NIRE and GFDL-GCTM models compared to the much weaker maxima simulated by the coarser MUTM, GISS, and CSU models. The coarsest grid is used by the TM2 model, however, which simulates moderate mixing ratios over the source regions, whereas the highest concentrations of any model are those simulated by the TM3 model with a relatively coarse grid. When averaged over the European source region from $0^{\circ}$ to $30^{\circ} \mathrm{E}$ longitude and from $40^{\circ}$ to $60^{\circ} \mathrm{N}$ latitude, there is no significant relationship between mean surface mixing ratio and model resolution.

Meridional transects of surface concentrations of anthropogenic tracers have frequently been interpreted in terms of meridional transport and interhemispheric exchange. Such an interpretation may be an oversimplification given the results presented in Fig. 4 because both the simulations and the observations show considerable longitudinal variation. Estimates of interhemispheric gradients from surface data depend strongly on the locations of observing stations, and may reflect 
Table 2. Simulated and observed $S F_{6}$ mole fraction (pptv) comparison at most measured locations indicated in Fig. 2 (Trans-Siberian transect is not included here)

\begin{tabular}{|c|c|c|c|c|c|c|c|c|c|c|c|c|c|c|}
\hline Station & Laditude & Longitude & $\begin{array}{l}\text { Observations } \\
\text { (pptv) }\end{array}$ & $\begin{array}{l}\text { ANU } \\
\text { (pptv) }\end{array}$ & $\begin{array}{l}\text { CCC } \\
\text { (pptv) }\end{array}$ & $\begin{array}{l}\text { CSU } \\
\text { (pptv) }\end{array}$ & $\begin{array}{l}\text { GFDL-GCTM } \\
\text { (pptv) }\end{array}$ & $\begin{array}{l}\text { GFDL-SKYHI } \\
\text { (pptv) }\end{array}$ & $\begin{array}{l}\text { GISS } \\
\text { (pptv) }\end{array}$ & $\begin{array}{l}\text { GISS-UVic } \\
\text { (pptv) }\end{array}$ & $\begin{array}{l}\text { MUTM } \\
\text { (pptv) }\end{array}$ & $\begin{array}{l}\text { NIRE } \\
\text { (pptv) }\end{array}$ & $\begin{array}{l}\text { TM2 } \\
\text { (pptv) }\end{array}$ & $\begin{array}{l}\text { TM3 } \\
\text { (pptv) }\end{array}$ \\
\hline Neumayer & -71.0 & -8.0 & 2.78 & 2.83 & 2.84 & 2.85 & 2.82 & 2.83 & 2.81 & 2.77 & 2.82 & 2.82 & 2.78 & 2.79 \\
\hline Tierra del Fuego & -54.9 & -68.5 & 2.78 & 2.84 & 2.84 & 2.85 & 2.82 & 2.83 & 2.82 & 2.78 & 2.83 & 2.83 & 2.78 & 2.80 \\
\hline Cape Grim, Tasmania & -40.7 & 144.7 & 2.79 & 2.86 & 2.88 & 2.86 & 2.84 & 2.85 & 2.83 & 2.80 & 2.84 & 2.85 & 2.80 & 2.83 \\
\hline Barbados & 13.2 & -59.4 & 3.14 & 2.94 & 3.02 & 3.00 & 3.06 & 3.02 & 2.98 & 3.07 & 2.98 & 3.10 & 3.06 & 3.04 \\
\hline Guam & 13.4 & 144.8 & 3.03 & 2.91 & 2.99 & 2.98 & 3.03 & 2.99 & 2.97 & 3.07 & 2.97 & 3.05 & 3.02 & 3.04 \\
\hline Kumukahi, Hawaii & 19.5 & -154.8 & 3.12 & 2.94 & 3.06 & 3.03 & 3.09 & 3.03 & 3.00 & 3.12 & 3.00 & 3.12 & 3.08 & 3.10 \\
\hline Izaña & 28.0 & -16.0 & 3.10 & 3.01 & 3.14 & 3.10 & 3.17 & 3.09 & 3.05 & 3.17 & 3.04 & 3.22 & 3.13 & 3.20 \\
\hline Bermuda & 32.4 & -64.7 & 3.20 & 3.05 & 3.12 & 3.13 & 3.16 & 3.12 & 3.07 & 3.19 & 3.04 & 3.24 & 3.12 & 3.19 \\
\hline North Carolina Tower* & 35.4 & -77.4 & 3.41 & 3.22 & 3.47 & 3.21 & 3.51 & 3.28 & 3.10 & 3.29 & 3.23 & 3.54 & 3.30 & 3.54 \\
\hline Tae Ahn Peninsula* & 36.7 & 126.1 & 3.25 & 3.05 & 3.31 & 3.23 & 3.28 & 3.65 & 3.12 & 3.29 & 3.12 & 3.34 & 3.23 & 3.45 \\
\hline Azores & 38.8 & -27.1 & 3.21 & 3.02 & 3.13 & 3.17 & 3.18 & 3.11 & 3.06 & 3.18 & 3.03 & 3.21 & 3.13 & 3.18 \\
\hline Utah* & 39.9 & -113.7 & 3.21 & 3.07 & 3.18 & 3.11 & 3.35 & 3.19 & 3.09 & 3.19 & 3.07 & 3.24 & 3.15 & 3.23 \\
\hline Wisconsin Tower* & 45.9 & -90.3 & 3.31 & 3.16 & 3.32 & 3.17 & 3.28 & 3.27 & 3.12 & 3.41 & 3.18 & 3.39 & 3.21 & 3.63 \\
\hline Hungary* & 47.0 & 16.4 & 3.42 & 3.54 & 3.55 & 3.25 & 3.79 & 3.39 & 3.16 & 3.42 & 3.26 & 3.70 & 3.29 & 3.98 \\
\hline Fraserdale* & 50.0 & -82.0 & 3.25 & 3.07 & 3.24 & 3.12 & 3.24 & 3.23 & 3.10 & 3.33 & 3.09 & 3.27 & 3.17 & 3.27 \\
\hline Mace Head, Ireland & 53.3 & -9.9 & 3.25 & 3.16 & 3.19 & 3.12 & 3.30 & 3.21 & 3.09 & 3.25 & 3.08 & 3.32 & 3.19 & 3.29 \\
\hline Cold Bay, Alaska & 55.2 & -162.7 & 3.20 & 3.00 & 3.15 & 3.10 & 3.18 & 3.15 & 3.07 & 3.19 & 3.07 & 3.18 & 3.14 & 3.21 \\
\hline Alert & 82.5 & -62.5 & 3.17 & 3.01 & 3.16 & 3.11 & 3.19 & 3.15 & 3.08 & 3.21 & 3.08 & 3.21 & 3.16 & 3.22 \\
\hline Atlantic transect 1 & 39.5 & -14.3 & 3.18 & 3.05 & 3.14 & 3.11 & 3.25 & 3.12 & 3.07 & 3.22 & 3.05 & 3.26 & 3.14 & 3.24 \\
\hline Atlantic transect 2 & 29.2 & -17.1 & 3.17 & 3.13 & 3.13 & 3.10 & 3.17 & 3.09 & 3.06 & 3.20 & 3.04 & 3.22 & 3.13 & 3.20 \\
\hline Atlantic transect 3 & 20.1 & -21.2 & 3.15 & 2.99 & 3.10 & 3.08 & 3.13 & 3.06 & 3.05 & 3.17 & 3.02 & 3.19 & 3.11 & 3.16 \\
\hline Atlantic transect 4 & 9.4 & -23.7 & 2.97 & 2.94 & 3.06 & 3.05 & 3.05 & 3.03 & 2.99 & 3.09 & 2.96 & 3.11 & 2.98 & 3.06 \\
\hline Atlantic transect 5 & -0.2 & -18.5 & 2.91 & 2.88 & 2.90 & 2.93 & 2.93 & 2.90 & 2.90 & 2.88 & 2.87 & 2.89 & 2.86 & 2.89 \\
\hline Atlantic transect 6 & -11.7 & -7.3 & 2.82 & 2.87 & 2.87 & 2.89 & 2.88 & 2.87 & 2.86 & 2.83 & 2.86 & 2.86 & 2.81 & 2.83 \\
\hline Atlantic transect 7 & -18.8 & 8.0 & 2.86 & 2.87 & 2.86 & 2.90 & 2.90 & 2.86 & 2.86 & 2.84 & 2.85 & 2.85 & 2.80 & \\
\hline Altantic transect 8 & -25.9 & 10.1 & 2.84 & 2.87 & 2.86 & 2.87 & 2.86 & 2.85 & 2.84 & 2.82 & 2.85 & 2.85 & 2.80 & 2.82 \\
\hline Atlantic transect 9 & -32.7 & 8.6 & 2.83 & 2.86 & 2.85 & 2.87 & 2.84 & 2.85 & 2.83 & 2.79 & 2.84 & 2.84 & 2.79 & 2.81 \\
\hline Atlantic transect 10 & -39.5 & 7.9 & 2.81 & 2.85 & 2.84 & 2.86 & 2.83 & 2.84 & 2.83 & 2.79 & 2.83 & 2.84 & 2.79 & 2.81 \\
\hline Atlantic transect 11 & -48.1 & 9.1 & 2.81 & 2.84 & 2.84 & 2.85 & 2.82 & 2.83 & 2.82 & 2.78 & 2.83 & 2.83 & 2.79 & 2.80 \\
\hline Atlantic transect 12 & -56.6 & 9.1 & 2.82 & 2.83 & 2.83 & 2.85 & 2.82 & 2.83 & 2.81 & 2.77 & 2.82 & 2.83 & 2.78 & 2.80 \\
\hline
\end{tabular}

The values have been extrapolated to mid-1993 using the average of the linear regression slope coefficients derived from the individual station data (in the case of Izaña and Neumayer, adequate 1993 data were available). All model values have been adjusted according to the revised emissions estimates described in the text.

* Not considered a "marine boundary location". 

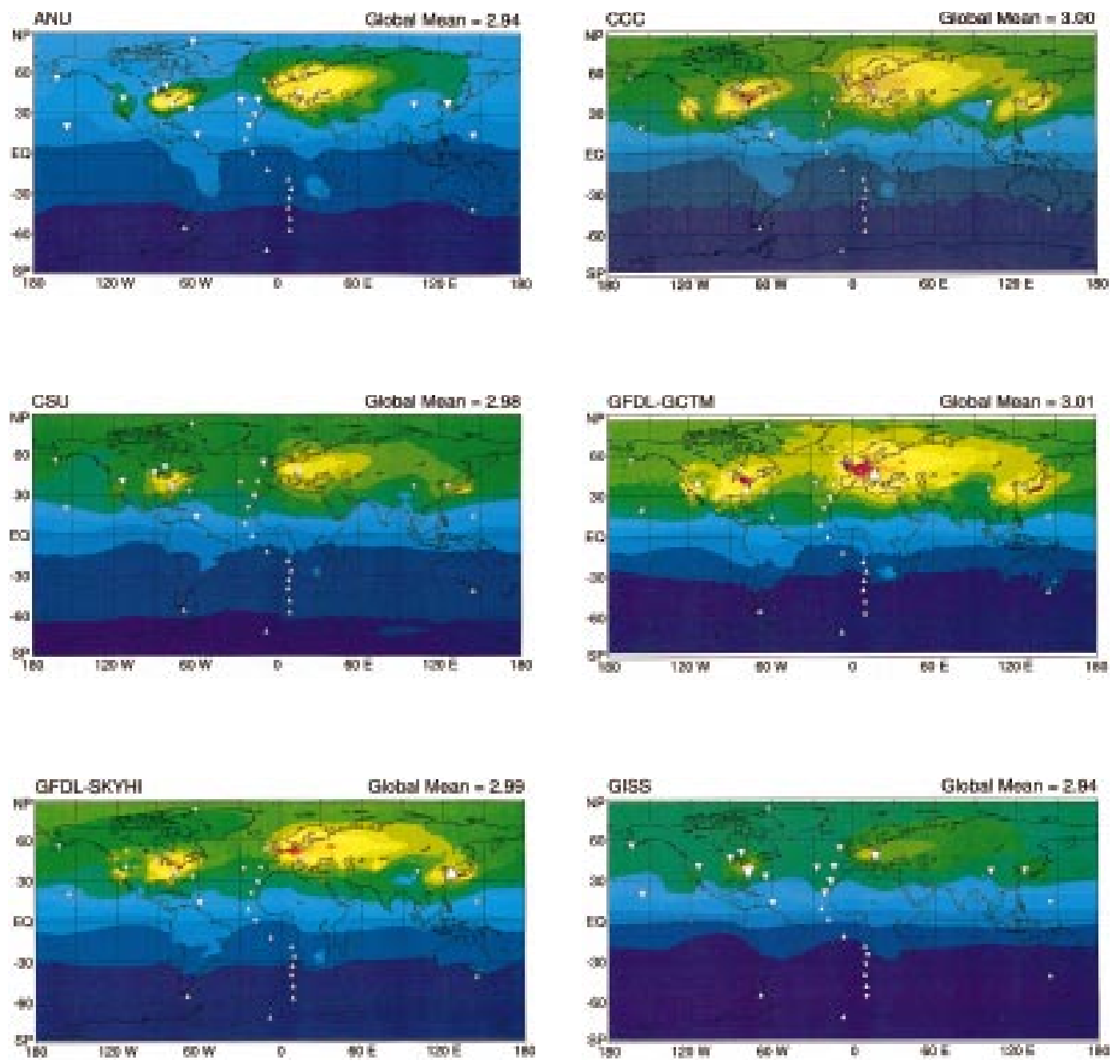

Fig. 4. Simulated annual mean surface mole fraction of $\mathrm{SF}_{6}$ (pptv) for each of 11 model calculations (emissions adjusted as described in the text). Contour interval is 0.05 pptv from 2.75 to 3.30 ; 0.1 from 3.30 to 3.80 ; and 0.20 from 3.8 to 4.20 pptv. Global means indicated are area-weighted annual means for the surface only. White triangles represent the deviation (simulated minus observed) for the station locations and Atlantic transect measurements (time-adjusted as described in the Fig. 3 caption). Upward-pointing triangles indicate model overestimates, and downward-pointing triangles indicate model underestimates with the magnitude defined in the legend.

the degree to which tracer mass is retained in the source regions against zonal or vertical mixing as well as meridional mixing. We note that the global surface mean mole fractions are significantly lower for those models with the weakest mean meridional gradients (ANU, CSU, MUTM, GISS) than for those with the strongest gradients (NIRE, GFDL-GCTM, TM3).

A longitudinal transect of surface $\mathrm{SF}_{6}$ mixing ratio extending eastward from the European source region across Eurasia was measured by Crutzen et al. (1998) aboard the Trans-Siberian Railroad. In the models, this transect is characterized by a gradient in concentration whose magnitude may reveal important differences among simulated transport. The measurements and simulations were not contemporaneous, so the simulated mixing ratio was extrapolated in time by using the linear trend to 

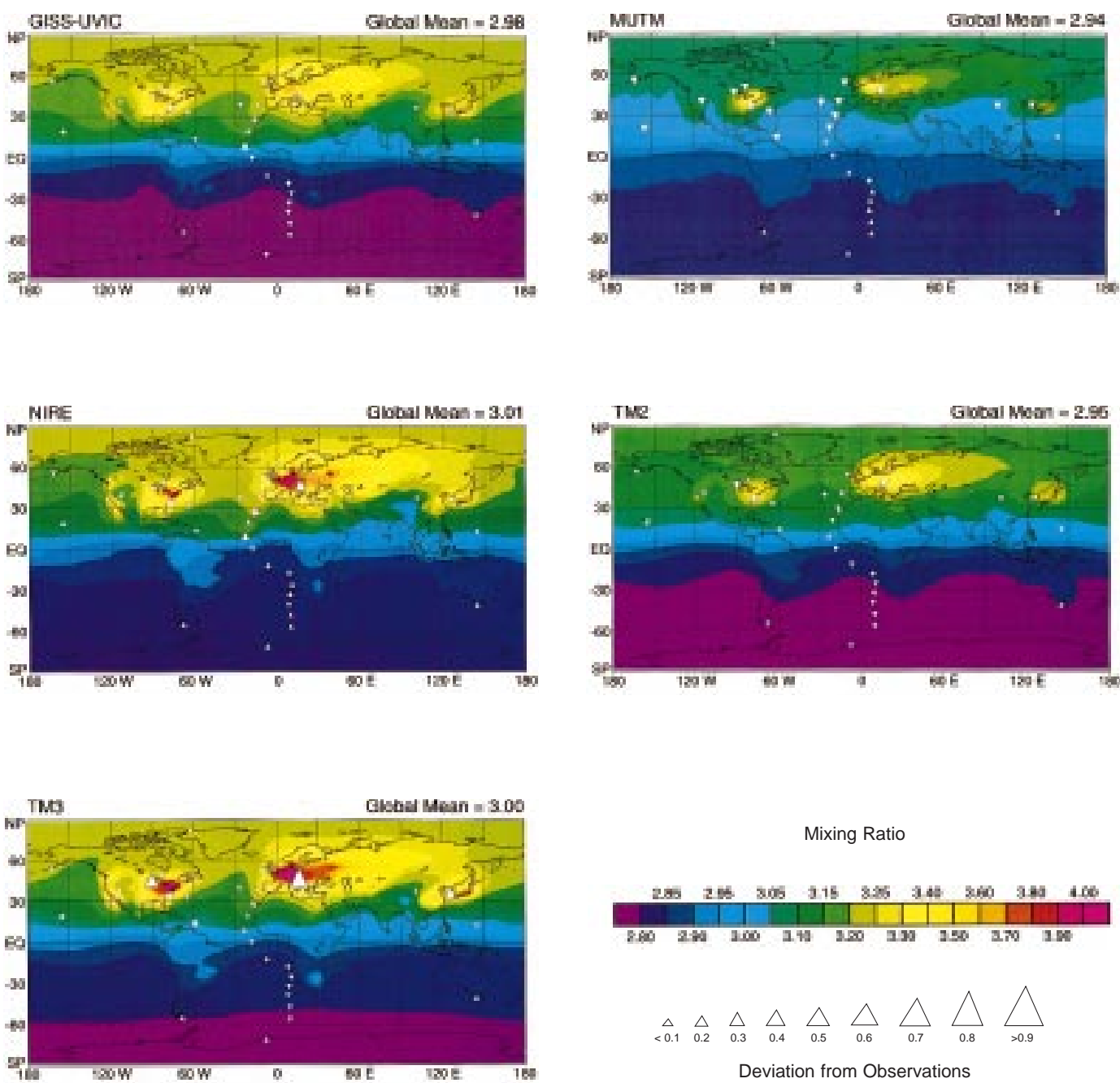

Fig. 4. (cont'd.)

each model's growth rate averaged along the transect in 1993. The simulated trend could only be estimated from 12 monthly mean values at each location in 1993 and these estimates varied considerably by model and by longitude. Comparison of the models to the data in Fig. 5a should therefore be made with caution. The prescribed emissions increase linearly with time, and all of the models exhibited stronger growth rates for the western part of the transect (nearest the emissions maximum). Using a longitudinally-dependent growth rate for the time extrapolation would steepen the west-east gradient in the extrapolated values.

To focus on the model-to-model differences, we compare in Fig. $5 \mathrm{~b}$ the deviation of $\mathrm{SF}_{6}$ mole fraction from its along-transect longitudinal mean. Some of the models overestimate the west-east gradient (ANU, CCC, GFDL-GCTM, GFDLSKYHI, GISS-UVic, NIRE, TM3), particularly near the western end of the transect, with the remainder performing better (CSU, GISS, MUTM, TM2). The simulated gradients represent 1993 conditions, and would be even stronger in 1996 due to the growth of emissions. The observations show surprisingly little longitudinal structure across this region, with less than $0.1 \mathrm{pptv}$ difference

Tellus 51B (1999), 2 
Figure 5a. Siberian rail observations and model predictions

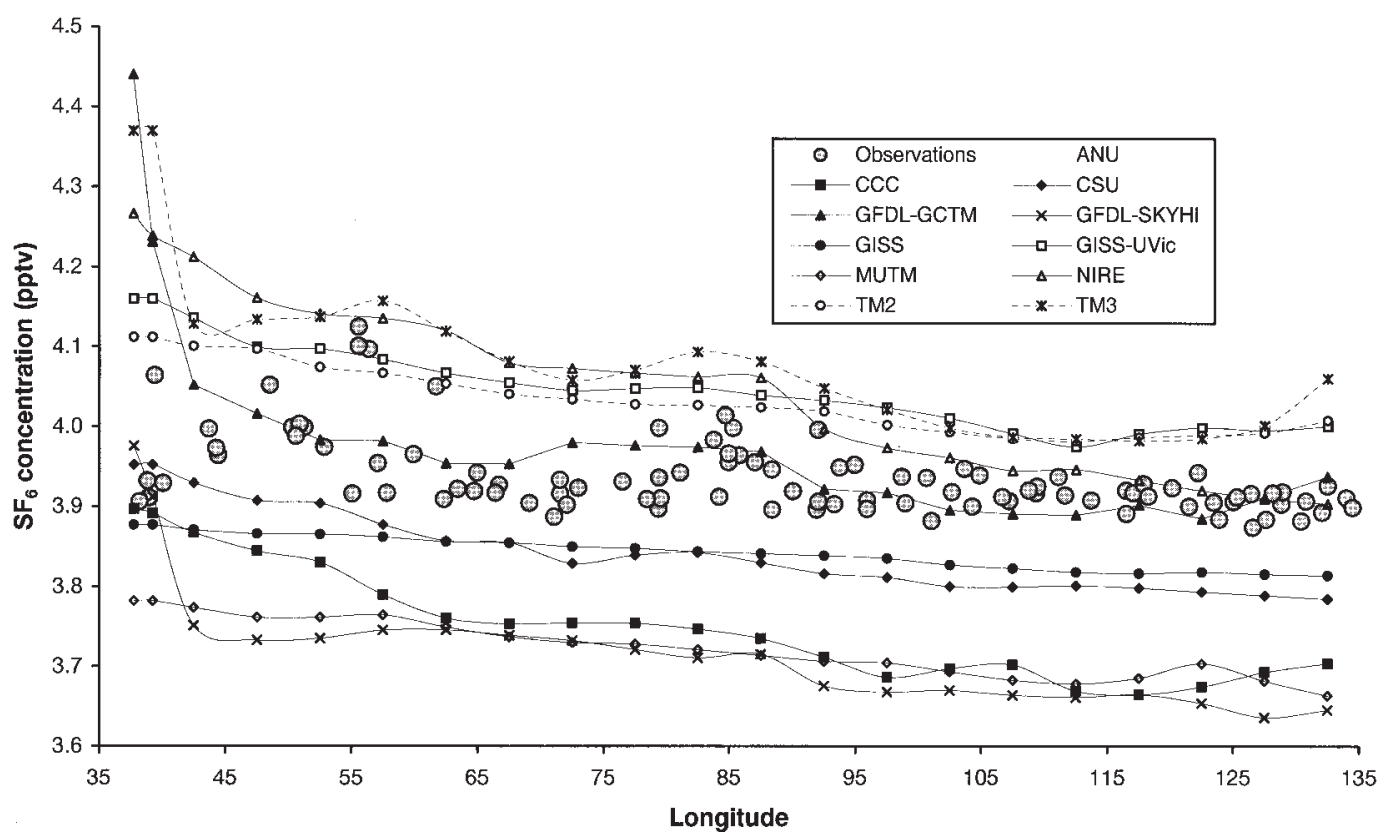

Figure 5b. Siberian rail observations and model prediction, deviation from

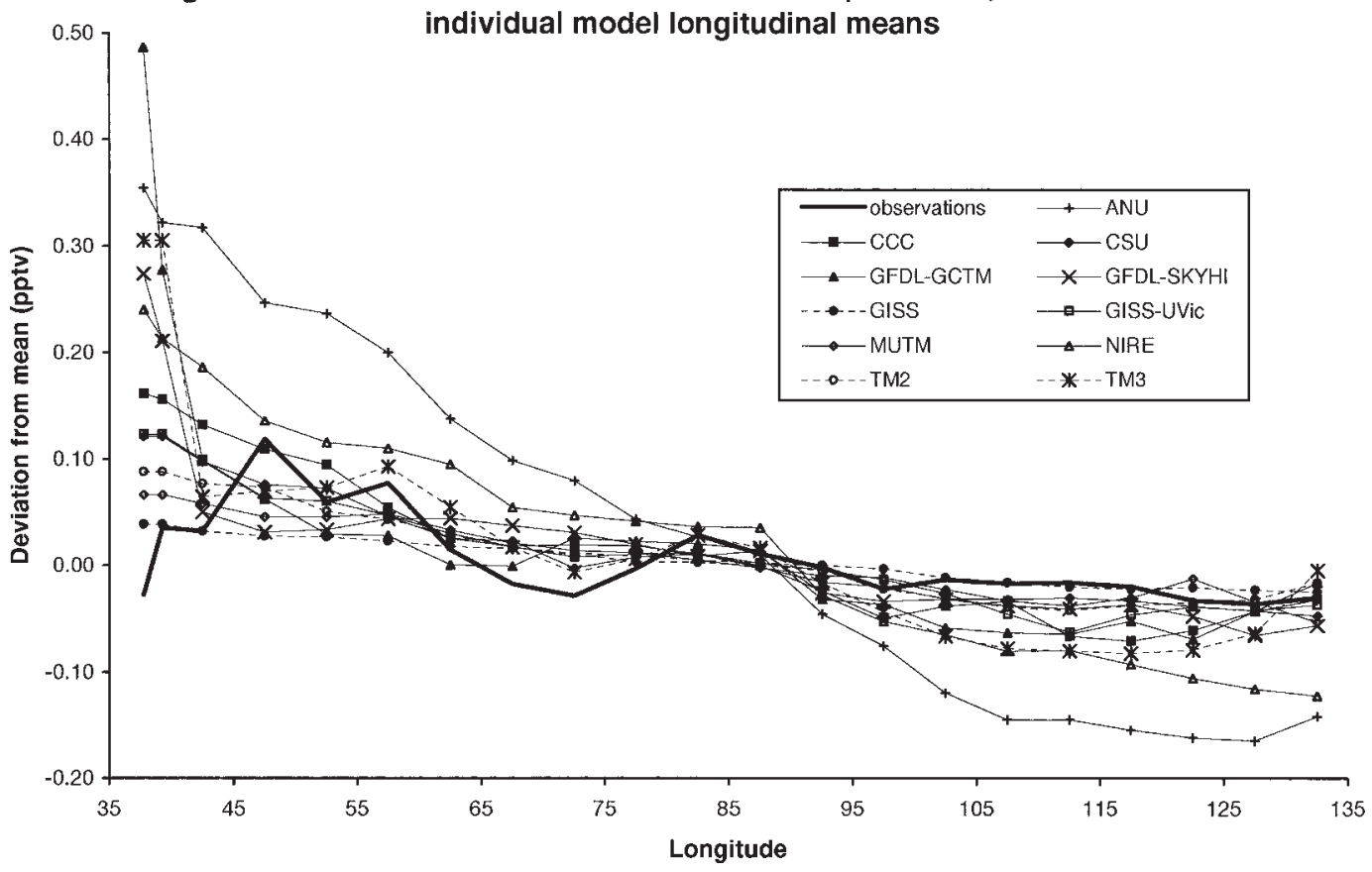


between Moscow and Vladivostok. It is possible that significant Siberian $\mathrm{SF}_{6}$ emissions, not prescribed in our emissions field, account for the weak observed gradient. For example, electrical and industrial infrastructure located along the Railroad itself would produce local $\mathrm{SF}_{6}$ maxima along the length of the Siberian transect. The observations are also quite "noisy" with considerable local-scale variance and as much as $0.2 \mathrm{pptv}$ difference between the eastbound and westbound legs of the transect. Crutzen et al. (1998) attribute these differences to different air-mass trajectories encountered en route.

None of the models simultaneously satisfy the constraints of the observed meridional gradient in the marine boundary layer and the longitudinal gradient across Eurasia. Such simultaneous matching of constraints could be accomplished by more vigorous horizontal mixing in the lower troposphere, reducing regional maxima in the source regions, and increasing values in the remote MBL. However, those models that matched the MBL measurements would have to compensate by allowing more vertical mixing of tracer to prevent overestimating the MBL data. Similarly, those models that matched the Eurasian transect measurements would require reduced vertical mixing to prevent underestimates of the westeast gradient.

\subsection{Zonal mean vertical and meridional structure}

Zonal mean cross-sections of annual mean simulated $\mathrm{SF}_{6}$ mole fraction for each model are compared in Fig. 6. All models show elevated values at the surface in the northern hemisphere source region. The models can be classified into two populations based on these cross-sections: one group (ANU, CSU, GISS, MUTM, and TM2) generates relatively weak vertical gradients over the northern extratropics, whereas a second group (CCC, both GFDL models, GISS-UVic, TM3, and especially NIRE) generate stronger vertical gradients over the source region. This probably reflects differences in the subgrid-scale parameterization of vertical transport or in the simulated thermal stability of the atmosphere among the models.

The ANU model exhibits much less spatial structure everywhere than the other models, except in the immediate vicinity of the emissions (cf. Fig. 4). The pole-to-pole difference in the midtroposphere simulated by ANU is only $0.15 \mathrm{pptv}$, compared to 0.25 for MUTM and $0.40 \mathrm{pptv}$ for TM3. This is consistent with the fossil fuel simulations in TransCom 1, in which ANU simulated a moderately strong zonal mean gradient at the surface, but almost no meridional gradient aloft. This model apparently traps tracer in the immediate vicinity of sources, but exhibits vigorous mixing in the free troposphere.

The division of the models into a "strongly mixed" and a "weakly mixed" population is consistent with the differences in simulated surface model fraction discussed above. Models that exhibit weak vertical mixing (NIRE, TM3, and the GFDL models) tend to accumulate more $\mathrm{SF}_{6}$ in the northern lower troposphere, and thus have stronger surface meridional gradients than the strongly mixed models. These models are generally successful at simulating the observed meridional gradient in the remote MBL (Fig. 3), but systematically overestimate $\mathrm{SF}_{6}$ at continental sites (WLEF, WITN, Hungary, and the western end of the Eurasian transect, see Figs. 4 and 5). The converse is true for models with large vertical mixing (CSU, GISS, MUTM, cf. Figs. 3 and 4). These results suggest that differences in parameterized vertical transport among the models, rather than differences in resolved horizontal advection, may account for most of the differences in meridional structure at the surface.

It is difficult to decide which population of models is closest to reality, because nearly all the

Fig. 5. (a) Longitudinal gradient of $\mathrm{SF}_{6}$ mole fraction (pptv) across Eurasia as simulated (using July/August model monthly means interpolated to measurement date) and measured (July 25 through August 12, 1996) along the route of the Trans-Siberian Railroad (Crutzen et al., 1998). The simulated mixing ratios were extrapolated to 1996 using each model's linear trend of transect-average mixing ratios for 12 monthly values reported for 1993. Model results have been averaged into $5^{\circ}$ longitudinal bins, except for the two western-most bins, which are $1.5^{\circ}$. ANU exhibited an anomalously high growth rate in this region, leading to extrapolated mixing ratios in excess of $4.5 \mathrm{pptv}$ across most of the transect; these values have not been plotted. (b) The deviation of $\mathrm{SF}_{6}$ mole fractions from the respective simulated and measured across-transect means.

Tellus 51B (1999), 2 
(a)

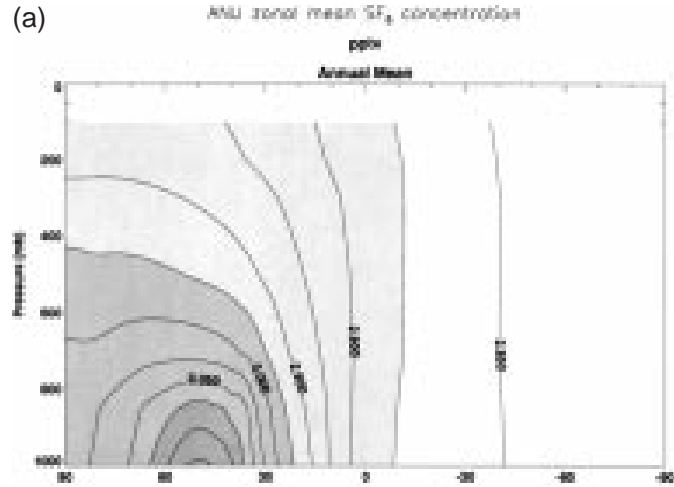

(c)

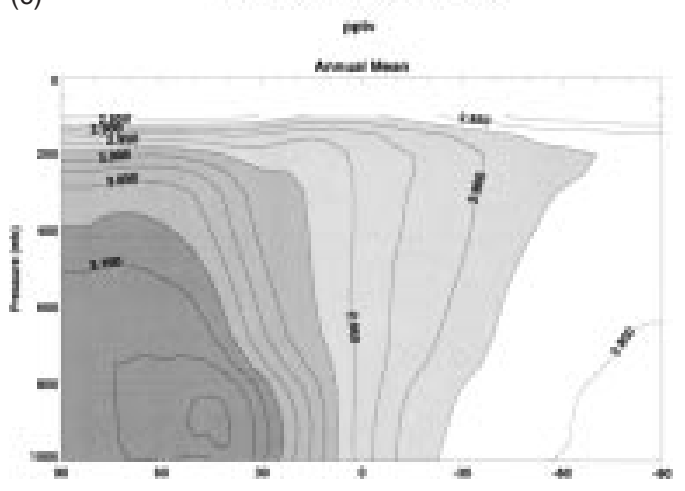

(e)

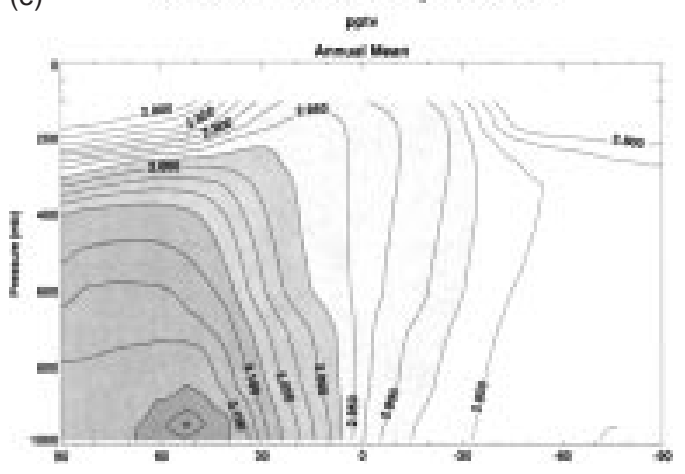

(b)

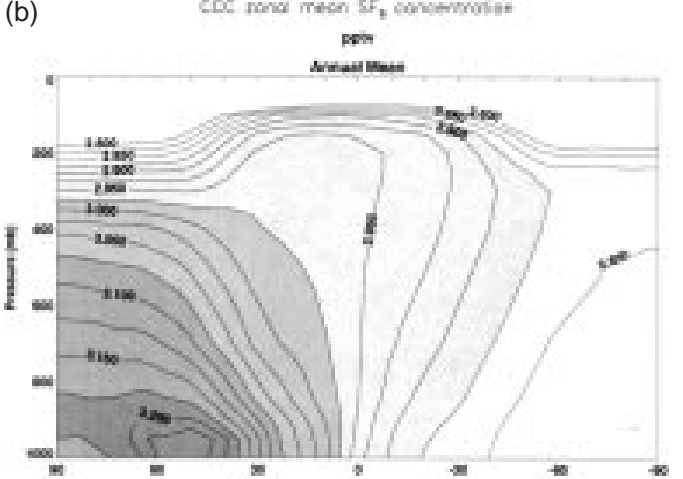

(d)

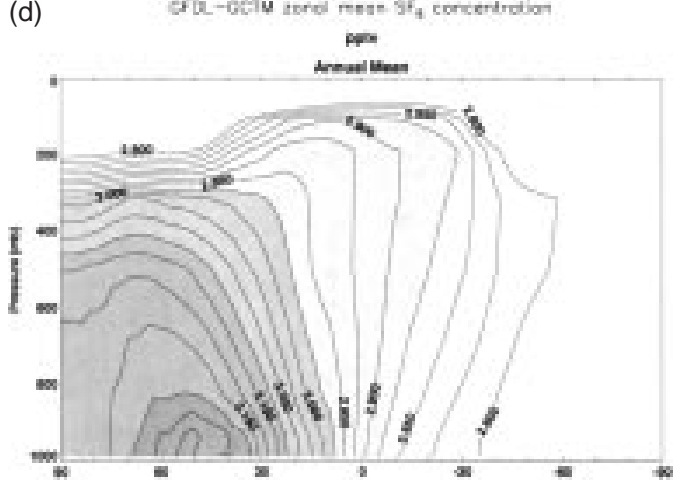

(f)

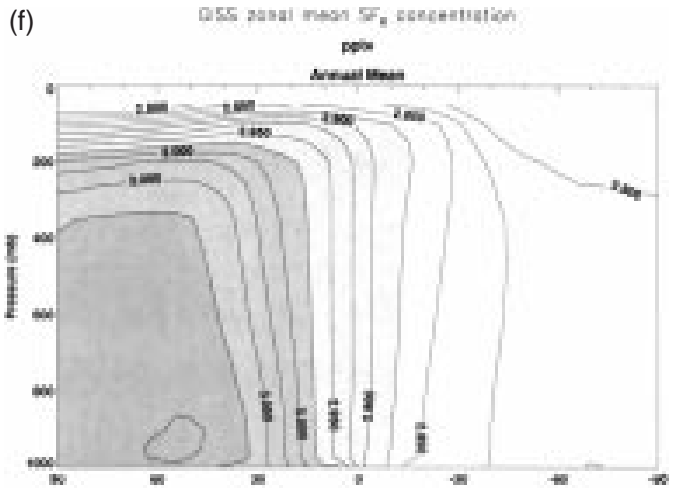

Fig. 6. Latitude-pressure cross-sections of annual mean simulated $\mathrm{SF}_{6}$ mole fraction (pptv) for 1993 for each model. The contour interval is 0.025 pptv, with shading thresholds at $2.875,2.975,3.075$, and 3.175 pptv

observational data is at the surface and the most striking differences between the two populations of models is in their simulated vertical structure. Vertical profiles through the depth of the troposphere over the source regions would be extremely helpful in falsifying one of the populations of models. To date, the only published vertical profiles of $\mathrm{SF}_{6}$ have been from stratospheric sampling programs (Harnisch et al., 1996; Patra et al., 1997); these data provide almost no constraint on the behavior of the TransCom models with their tropospheric focus. Recent efforts to measure vertical 
(g)
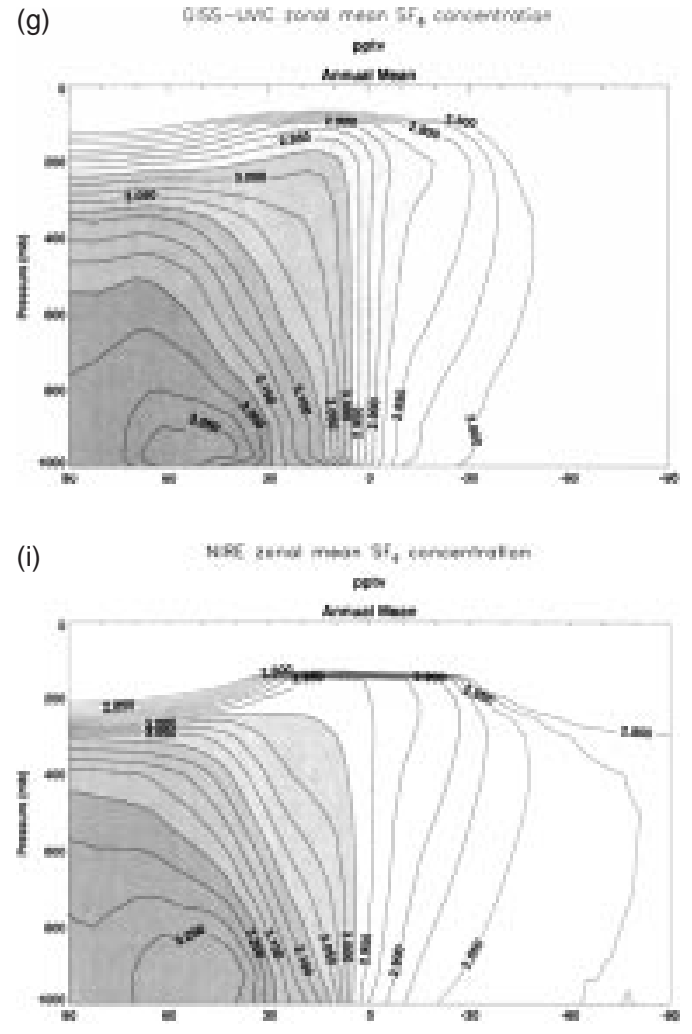

$(\mathrm{k})$

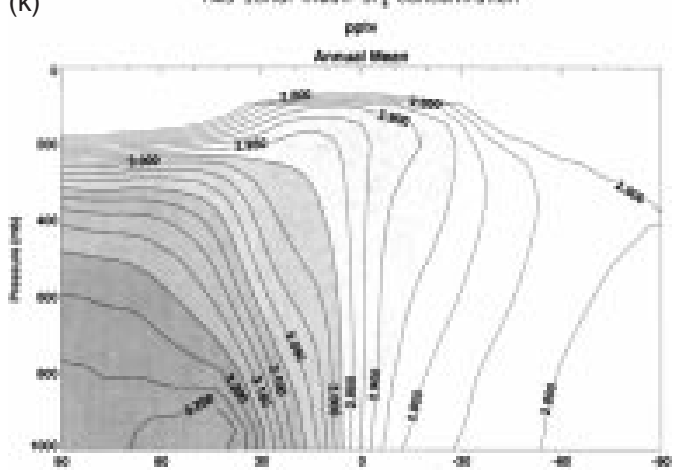

Fig. 6. (Continued.)

profiles in the lower troposphere over Tasmania (Ray Langenfelds, personal communication) and at several locations in the upper troposphere (the LACE experiment, Eric Ray, personal communication) will be much more helpful in this regard.

All models except ANU show a reversed vertical gradient in the southern hemisphere, with $\mathrm{SF}_{6}$
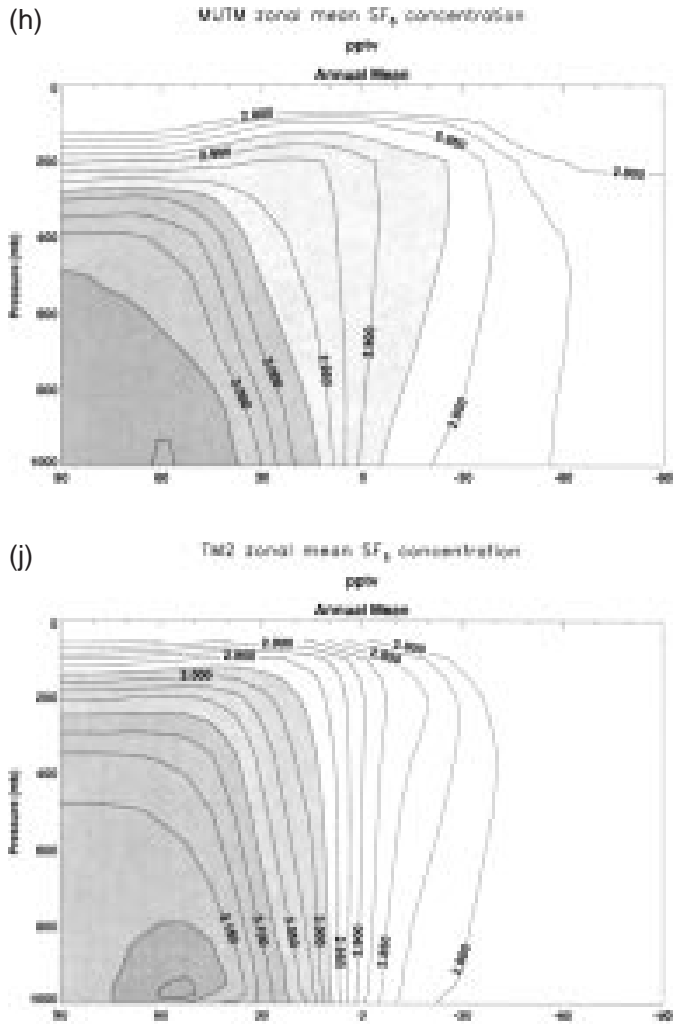

increasing with height. This suggests that southward penetration of $\mathrm{SF}_{6}$ across the equator occurs primarily in the upper troposphere. Interestingly, this interhemispheric penetration is most pronounced for the models that exhibit the strongest vertical gradient in the northern hemisphere. This result suggests that great care must be taken in

Tellus 51B (1999), 2 
the interpretation of observed surface meridional profiles in terms of interhemispheric mixing. We return to this problem in Subsection 4.1 below.

\subsection{Time series analysis at selected stations}

In this section we describe the performance of the different models at particular sampling sites. The participants were asked to report the $\mathrm{SF}_{6}$ concentration at specified sites, with the highest time resolution deemed appropriate for the particular model. Each participating group used their own standard horizontal and vertical interpolation scheme to determine the simulated concentration at the chosen sites.

The temporal variability of $\mathrm{SF}_{6}$ concentration was compared to observed high-resolution timeseries at two television tower monitoring sites (Fig. 7). In most cases, the differences between the first and third quartiles is reasonably well simulated. The highest concentration events are not simulated by any of the models. This is to be expected since the single point tower observations capture local scale gusts, fronts and other features not included in the large scale models. The models with the smallest variability on synoptic time scales have either coarse spatial resolution (TM2), coarse temporal resolution of winds (MUTM, TM2), or coarse temporal resolution of convection (TM2, GISS), so they cannot be expected to represent high concentration "events" of short duration.

The degree to which the simulations capture the temporal structure of $\mathrm{SF}_{6}$ variability was examined by comparing the autocorrelation function at these two sites. Fig. 8 compares the simulations at the two television towers in terms of the autocorrelation function. At both sites the autocorrelation of the observations decreases much more quickly than in the model simulations: the $50 \%$ point is reached in the observations at a lag of $6 \mathrm{~h}$ at WITN and at about $10 \mathrm{~h}$ at WLEF. This point is reached by the simulations between 18 and $48 \mathrm{~h}$ at WITN and between 15 and $48 \mathrm{~h}$ at WLEF. This reflects the finite resolution, both in space and time, of the model results. This is especially apparent for the models which use monthly mean convection statistics (TM2 and GISS). The NIRE autocorrelation function at WITN contains a small diurnal signal, for which there is an indication in the observations, but which is not present in the other models. This is interesting given that the NIRE model does not represent vertical transport by subgrid-scale convective mixing, although it does use a stabilitydependent formulation of the depth of the planetary boundary layer (Taguchi, 1996).

Simulated seasonal cycles for Izaña (IZO, $20^{\circ} \mathrm{N}$, $16^{\circ} \mathrm{W}, 2367 \mathrm{~m}$ elevation) and for the Antarctic coastal station Neumayer (NEU, $71^{\circ} \mathrm{S}, 8^{\circ} \mathrm{W}, 42 \mathrm{~m}$ elevation) are compared to observations in Fig. 9. The emissions of $\mathrm{SF}_{6}$ are not known to exhibit seasonality and have been incorporated into the experiment as such. The mean seasonal variability in $\mathrm{SF}_{6}$ concentration shown in Figure 9 therefore arises entirely from seasonal transport processes. The seasonal cycle at Izaña, a mid-tropospheric, mountaintop station located to the south of a source region, has two maxima, in the spring and autumn, with minima in the summer and winter. Back-trajectories calculated from 1991-1997 ECMWF data (Maiss, unpublished data) show that both maxima coincide with periods of elevated westerly air mass transport from latitudes higher than $40^{\circ} \mathrm{N}$ while the minima reflect transport of air from Africa. The autumn maximum and the winter minimum are further enhanced by a seasonality in the altitude of the originating air masses which is, on average, hundreds of meters lower in autumn compared to spring.

At Neumayer, seasonality is somewhat weaker (peak-to-peak amplitude of less than 0.02 pptv vs. 0.04 pptv at Izaña), with a well-defined maximum in the austral spring and minimum values in the austral autumn (February through April). The Antarctic seasonal cycle reflects periodicity in the input of $\mathrm{SF}_{6}$ into the southern hemisphere, with a phase lag determined by the transport time from the Equator to the station. Comparisons of the simulations to the data must be interpreted with caution, because the accuracy of the monthly observations is estimated at $0.01 \mathrm{pptv}$ at best (M. Maiss, personal communication), more than $30 \%$ of the observed range of variation at the Antarctic station.

All the models capture the fact that the seasonal cycle is stronger at Izaña than Neumayer. At Izaña, most models capture the absolute amplitude but only TM2 and MUTM simulate the observed double-peaked cycle with approximately correct phase. At Neumayer, the SKYHI and TM2 models simulate best the observed seasonal cycle. 

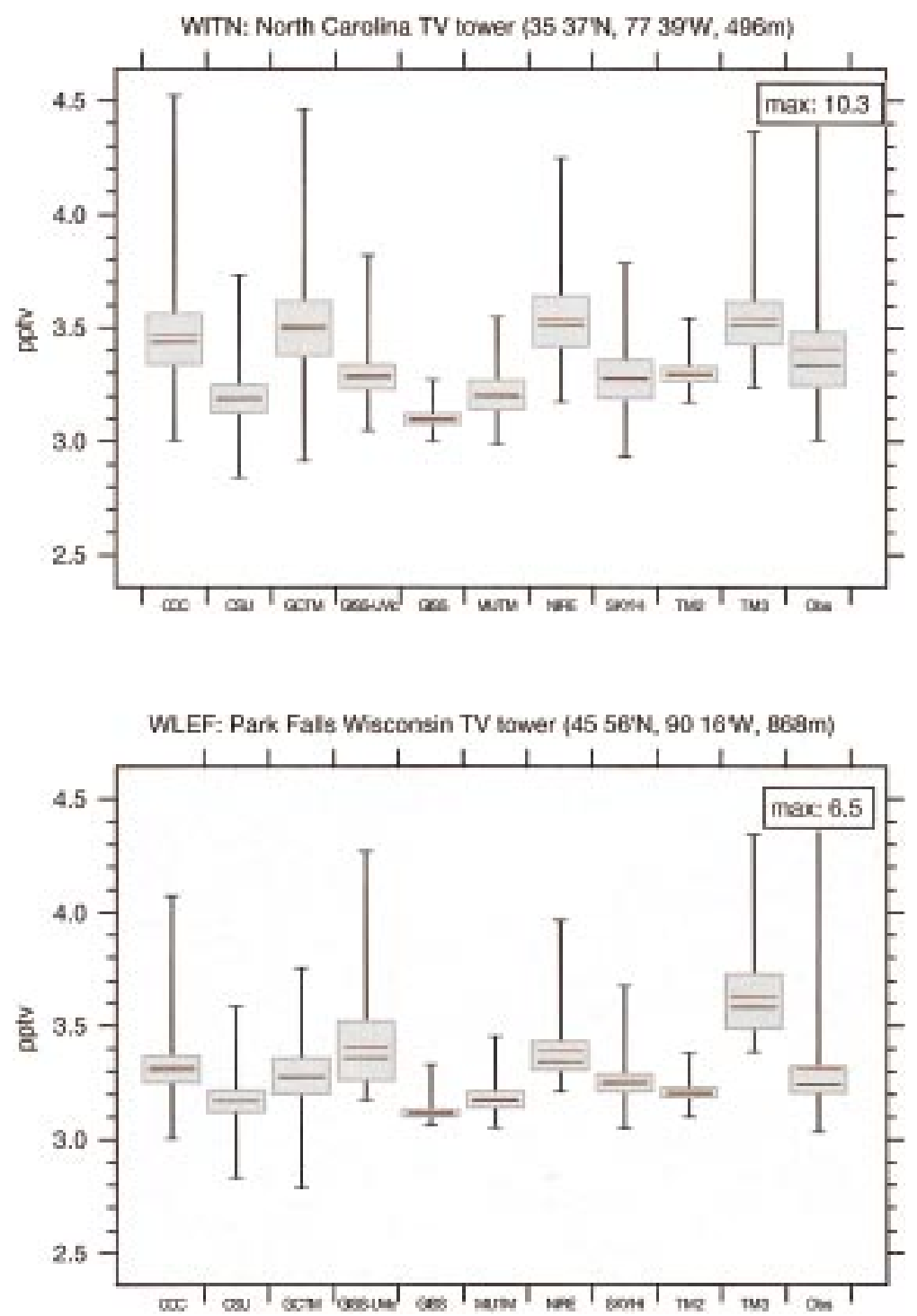

Fig. 7. Summary statistics of the model simulations at two television towers (WITN, North Carolina, $35^{\circ} 37^{\prime} \mathrm{N}$, $77^{\circ} 39^{\prime} \mathrm{W}, 496 \mathrm{~m}$ elevation and WLEF, Wisconsin, $45^{\circ} 56^{\prime} \mathrm{N}, 90^{\circ} 16^{\prime} \mathrm{W}, 868 \mathrm{~m}$ elevation). The monitoring program at these sites started in 1995 , so the data were extrapolated back in time to January 1993 by subtracting the global linear trend of $0.202 \mathrm{pptv} / \mathrm{yr}$. The "errorbars" show minimum and maximum, the upper (lower) borders of the boxes show the third(first) quartile of the simulated $\mathrm{SF}_{6}$ concentrations. The horizontal lines within the boxes denote the mean (gray), and median (black) of the simulated concentration. Also shown are the similar statistics obtained from the hourly observations at these sites (D. Hurst, NOAA-CMDL, personal communication). Time series data were not available for the ANU model. 
Figure 8a. Autocorrelation function at the WITN Tower

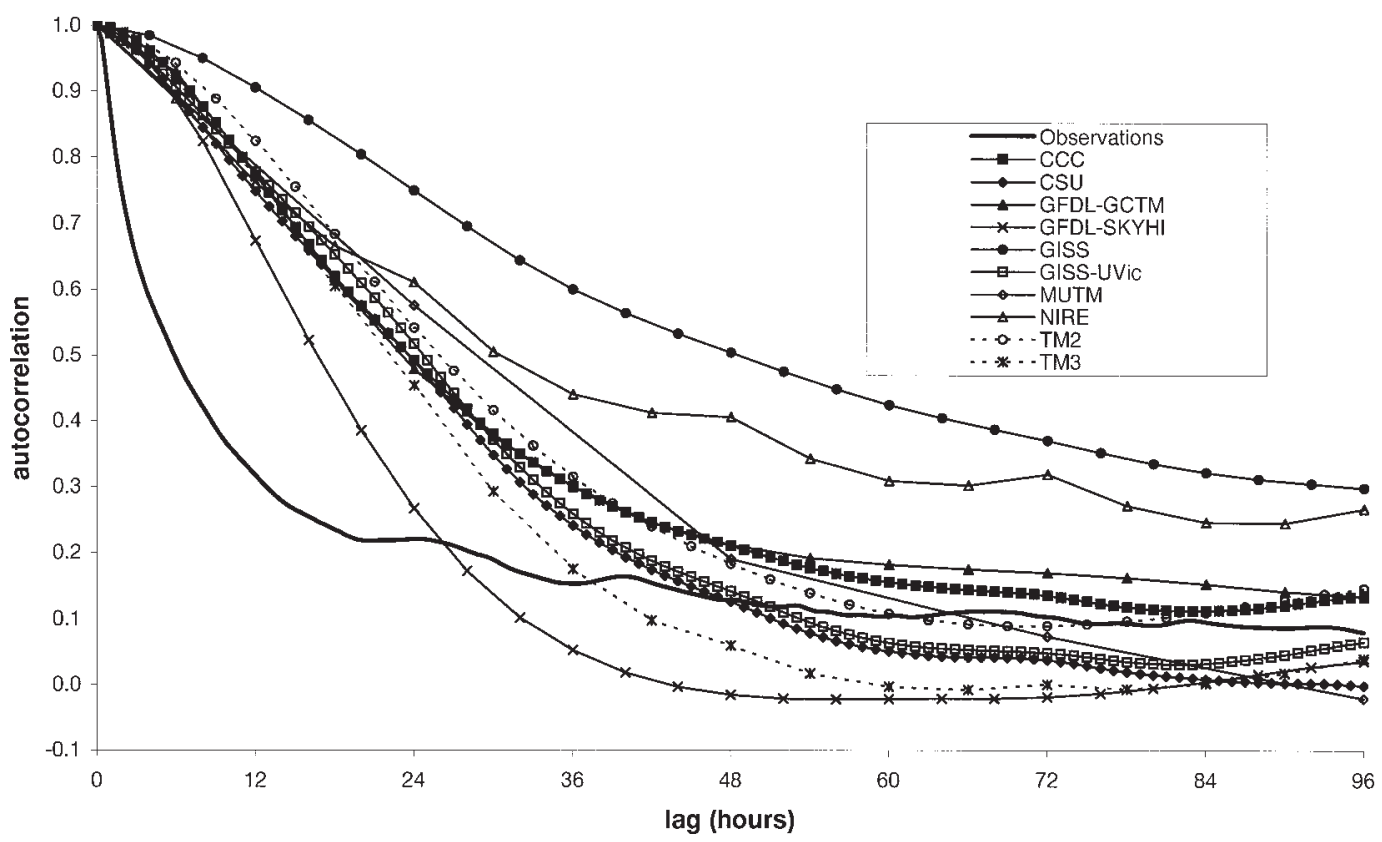

Figure 8b. Autocorrelation function at the WLEF Tower

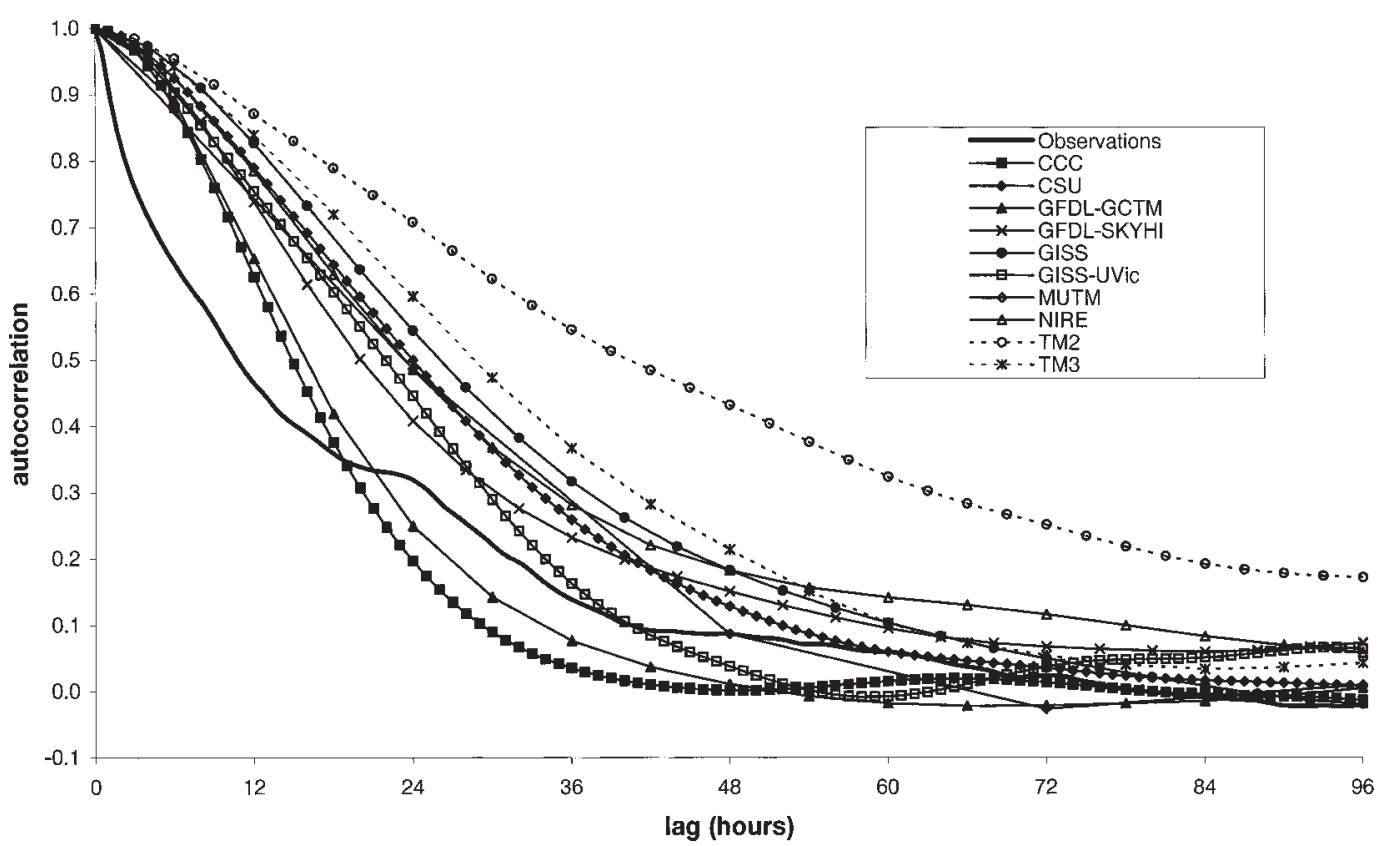

Tellus 51B (1999), 2 
Table 3. The reduced $X^{2}$ (in pptv) of the seasonal model simulation from observations at Izaña (IZO, $20^{\circ} \mathrm{N}, 16^{\circ} \mathrm{W}, 2367 \mathrm{~m}$ elevation) and at Neumayer (NEU, $71^{\circ} \mathrm{S}, 8^{\circ} \mathrm{W}, 42 \mathrm{~m}$ elevation), computed with the formula:

$r X^{2}=\sqrt{\frac{\sum\left(\left(\chi_{\mathrm{i}}-\chi_{\mathrm{obs}}\right) / \sigma\right)^{2}}{12}}$,

where the sum is over 12 months

\begin{tabular}{lcc}
\hline Models & Izaña & Meumayer \\
\hline CCC & 1.00 & 0.97 \\
CSU & 0.85 & 0.68 \\
GFDL-GCTM & 1.10 & 0.66 \\
GFDL-SKYHI & 0.89 & 0.67 \\
GISS & 0.65 & 1.21 \\
GISS-UVic & 0.79 & 0.43 \\
MUTM & 0.80 & 0.83 \\
NIRE & 0.85 & 1.23 \\
TM2 & 0.51 & 0.37 \\
TM3 & 0.63 & 0.38 \\
\hline
\end{tabular}

The seasonal amplitude is underestimated by the CSU and NIRE models and overestimated by the CCC and TM3 models. The GISS and MUTM models show the minimum too early in austral summer. The maximum in austral spring is simulated late by the CSU model and too early by the CCC, GISS, and MUTM models. A summary of the statistics of the seasonal cycle is provided in Table 3, which lists the reduced chi-squared of the model simulation and the observations.

\section{Intercomparison of the simulated transport}

\subsection{Interhemispheric transport exchange times}

Interhemispheric transport may to first order be described in terms of a two-box model, in which mass differences between the boxes (representing the hemispheres) are damped out with a time scale $\tau_{\text {ex }}$ (Czeplak and Junge, 1974; Weiss et al., 1983; Heimann et al., 1986). The time-scale $\tau_{\text {ex }}$ is a useful transport diagnostic because it collapses all the transport mechanisms into a single parameter which can be compared across simulations and to observations. Although the two-box formulation has been used to estimate atmospheric mixing from observed meridional profiles of trace gases, the value of $\tau_{\mathrm{ex}}$ is sensitive to the method of calculation (Jacob et al., 1987; Levin and Hesshaimer, 1996; Law et al., 1996) and to the meridional distribution of emissions of the tracer used (Plumb and McConalogue, 1988).

In a two-box model of the atmosphere in steadystate, $\tau_{\text {ex }}$ can be expressed as,

$\tau_{\mathrm{ex}}=\frac{2 \Delta M}{\Delta S}$,

where $\Delta M=M_{\mathrm{N}}-M_{\mathrm{S}}$ denotes the $\mathrm{SF}_{6}$ mass difference between the northern and southern hemispheres, and $\Delta S$ denotes the difference in the emission of $\mathrm{SF}_{6}$ masses between the hemispheres. The steady-state assumption can be relaxed and $\tau_{\text {ex }}$ can be computed on an instantaneous basis as,

$\tau_{\mathrm{ex}}=\frac{2 \Delta M}{\Delta S-\mathrm{d} \Delta M / \mathrm{d} t}$.

Critical to the calculation of $\tau_{\mathrm{ex}}$ is the way in which the hemispheric masses $M_{\mathrm{N}}$ and $M_{\mathrm{S}}$ are estimated. Table 4 shows $\tau_{\text {ex }}$ based on both model results and measurements comprising different approximations for $\Delta M$. Interhemispheric exchange times were calculated both for the October-November period, to facilitate comparison with the observational $\tau_{\mathrm{ex}}$ from the Atlantic transect, and as annual means, which are more representative of overall model performance. To highlight relative differences among the models, the annual mean $\tau_{\text {ex }}$ values are also ranked from fastest to slowest.

In the first case, labeled " $S-S \tau_{\text {ex }}(1 \mathrm{D})$ ", $\tau_{\text {ex }}$ was computed using (1). The hemispheric mean $\mathrm{SF}_{6}$ mixing ratios were based on the October/ November 1993 Atlantic transect $\mathrm{SF}_{6}$ measurements with a 1 November, 1993 emissions rate interpolated from the global estimates of Levin and Hesshaimer (1996). Interhemispheric exchange times varied between 1 and 2 years for both the steady-state case and the instantaneous case [calculated from (2) and labeled " $\tau_{\text {ex }}(1 \mathrm{D})$ "] This 1D method, often used to estimate interhemispheric exchange from field programs, implicitly

Fig. 8. Temporal autocorrelation function for the model fraction of $\mathrm{SF}_{6}$ at the two tall television towers, as simulated and observed. Time series data were not available for the ANU model. 
Figure 9a. Detrended $\mathbf{S F}_{6}$ Seasonal Cycle: Izana

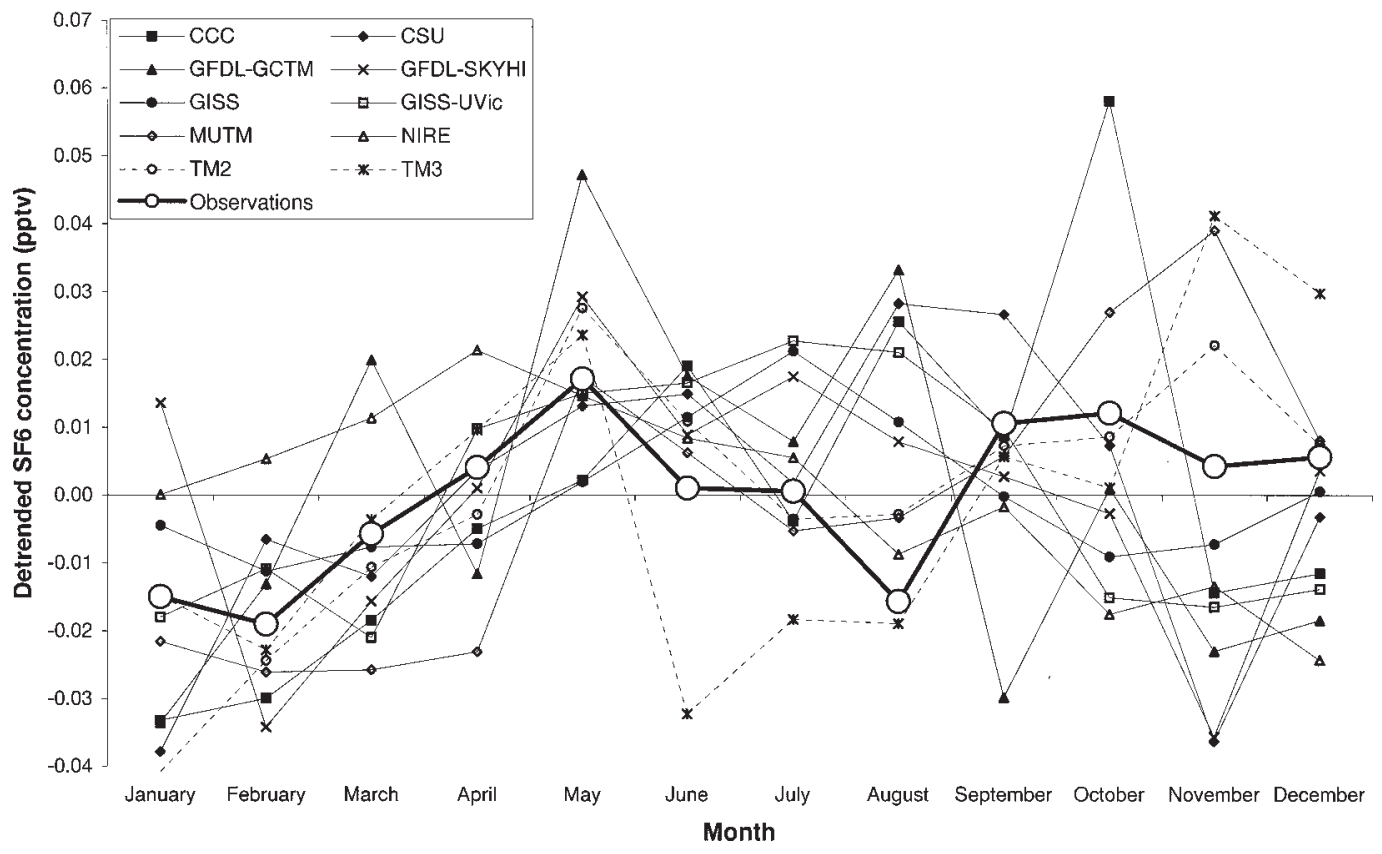

Figure 9b. Detrended $\mathrm{SF}_{6}$ Seasonal Cycle: Neumayer

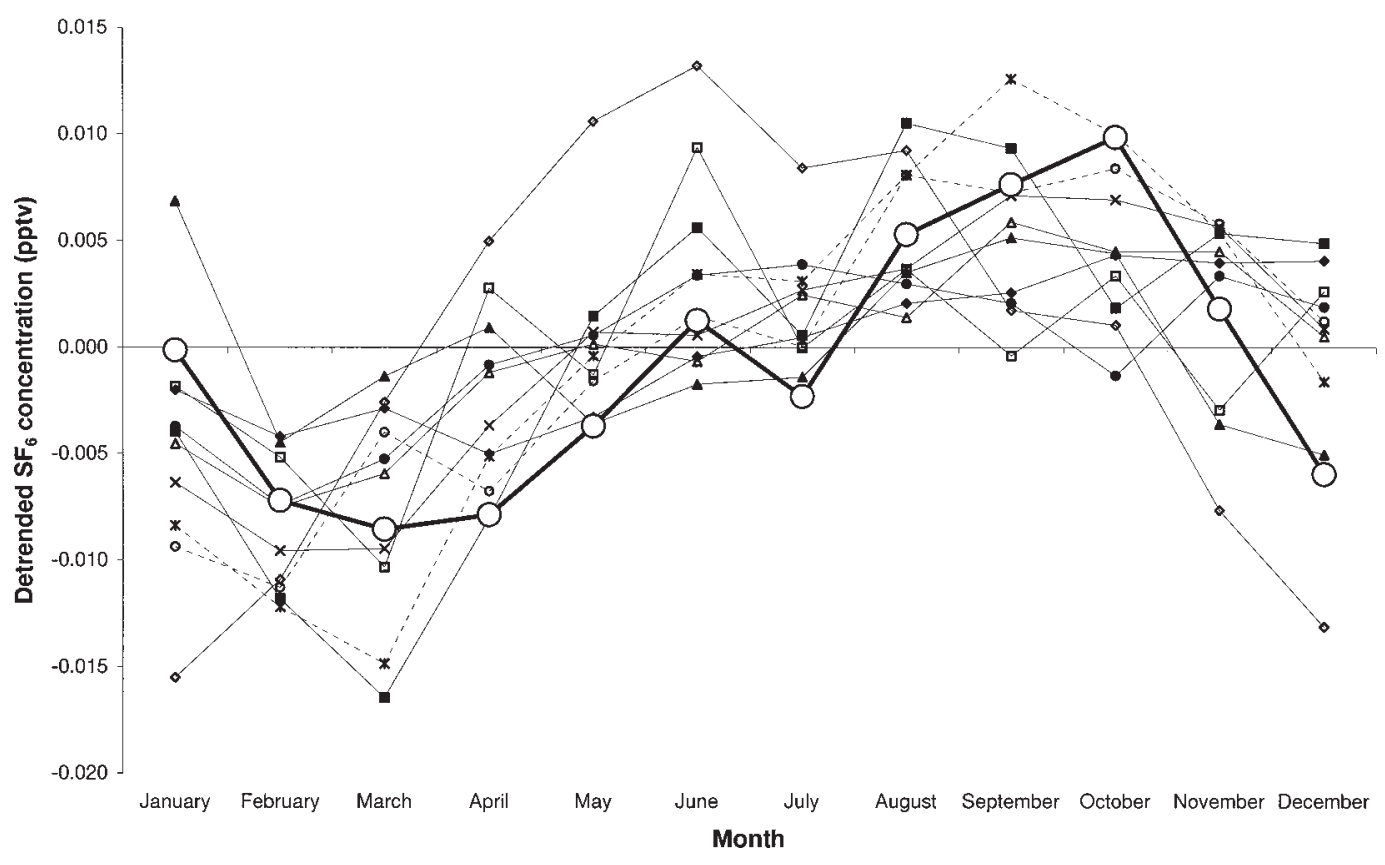


Table 4. Interhemispheric exchange times (years) derived from the model output and the Atlantic transect measurements

\begin{tabular}{|c|c|c|c|c|c|c|c|}
\hline & \multirow{2}{*}{$\begin{array}{c}\text { Oct } / \text { Nov } \\
S-S \tau_{\mathrm{ex}}\end{array}$} & \multicolumn{6}{|c|}{ Annual } \\
\hline & & $\tau_{\mathrm{ex}}(1 \mathrm{D})$ & rank & $\tau_{\mathrm{ex}}(2 \mathrm{D})$ & rank & $\tau_{\mathrm{ex}}(3 \mathrm{D})$ & rank \\
\hline $\mathrm{ANU}$ & 0.79 & 0.77 & 1 & 0.94 & 1 & 0.55 & 1 \\
\hline $\mathrm{CCC}$ & 1.31 & 1.34 & 6 & 1.55 & 6 & 0.58 & 2 \\
\hline $\mathrm{CSU}$ & 0.95 & 1.09 & 3 & 1.15 & 3 & 0.69 & 4 \\
\hline GFDL-GCTM & 1.46 & 1.55 & 7 & 1.68 & 7 & 0.84 & 6 \\
\hline GFDL-SKYHI & 0.92 & 1.25 & 5 & 1.46 & 5 & 0.73 & 5 \\
\hline GISS & 0.88 & 1.12 & 4 & 1.17 & 4 & 0.89 & 8 \\
\hline GISS-UVic & 1.64 & 1.89 & 10 & 2.05 & 11 & 1.26 & 10 \\
\hline MUTM & 0.76 & 0.97 & 2 & 1.13 & 2 & 0.64 & 3 \\
\hline NIRE & 1.97 & 2.03 & 11 & 1.97 & 9 & 0.85 & 7 \\
\hline TM2 & 1.42 & 1.56 & 8 & 1.77 & 8 & NA & NA \\
\hline TM3 & 1.60 & 1.80 & 9 & 2.01 & 10 & 1.05 & 9 \\
\hline Observations & 1.34 & & & & & & \\
\hline
\end{tabular}

In the case of the $1 \mathrm{D}$ estimates, all the measurement locations north (south) of the equator were averaged weighted by the cosine of latitude to estimate the northern (southern) hemisphere mean $\mathrm{SF}_{6}$ mixing ratios. The monthly mean 1993 model predictions for the Atlantic measurement locations were interpolated from the monthly means to the measurement dates. 3D tracer mass was unavailable for the TM2 model.

assumes that each point measurement is both zonally and vertically representative. This is probably quite unrealistic because Figs. 4 and 6 clearly demonstrate that the Atlantic transect is neither zonally or vertically representative.

The hemispheric masses were also computed from the global distribution of surface mixing ratio, assuming that each surface point represents a column mean. These masses were then used in (2) to calculate an instantaneous exchange time labeled " $\tau_{\text {ex }}(2 \mathrm{D})$ " (Table 4). The interhemispheric exchange times calculated in this fashion are larger than $\tau_{\text {ex }}$ (1D) for all the models except NIRE. Higher mole fractions in longitudinal regions are strongly influenced by $\mathrm{SF}_{6}$ source areas in eastern North America and Western Europe. The values of $\tau_{\text {ex }}$ (2D) assume that each surface point represents a column mean. The ranking of the $\tau_{\mathrm{ex}}$ values among models changes very little in going from the 1D station-based, to the 2D surface-based estimation. The extent to which the $2 \mathrm{D} \tau_{\mathrm{ex}}$ increases over the 1D case also reflects the degree to which the models mix $\mathrm{SF}_{6}$ zonally and vertically. For example, those models that exhibit strong vertical mixing exhibit $2 \mathrm{D} \tau_{\mathrm{ex}}$ times that are less affected by the inclusion of source regions because they retain less tracer near the surface in those regions (see Subsection 3.2).

Finally, $\Delta M$ was computed using the 3-dimensional mean mixing ratios and (2). Interhemispheric exchange times obtained in this way are true to the spirit of the two-box mixing model in that they represent the true hemispheric masses of each box. Not surprisingly, the interhemispheric exchange times calculated from 3D monthly means are much lower than their 2D analogs.

Using the full 3D mixing ratios to calculate $\tau_{\text {ex }}$ produces shifts relative to the other estimates of $\tau_{\mathrm{ex}}$ which are much more pronounced than the changes in ranking between the $1 \mathrm{D}$ and $2 \mathrm{D}$ calculations. Models that exhibit generally greater ver-

Fig. 9. Seasonal cycles (model and observations) for the (a) northern hemisphere station Izaña (IZO, $20^{\circ} \mathrm{N}, 16^{\circ} \mathrm{W}$, $2367 \mathrm{~m}$ elevation) on Tenerife and for (b) the Antarctic station Neumayer (NEU, $71^{\circ} \mathrm{S}, 8^{\circ} \mathrm{W}, 42 \mathrm{~m}$ elevation). The model simulations have been detrended by subtracting the annual mean and a linear trend of $0.201 \mathrm{pptv} / \mathrm{yr}$ prior to forming monthly averages. The biweekly observations of $\mathrm{SF}_{6}$ for 1993 have been aggregated to monthly averages and subsequently detrended. Time series data were not available for the ANU model.

Tellus 51B (1999), 2 
tical mixing tend to have the lowest $\tau_{\mathrm{ex}}$ values (ANU, CSU, MUTM, and GISS), but for some models $\tau_{\mathrm{ex}}(3 \mathrm{D})$ is drastically different from $\tau_{\mathrm{ex}}$ (2D). The CCC model has one of the slowest exchange times as estimated from surface gradients, yet is one of the fastest when true massweighted means are used. The GISS model, on the other hand, exhibits a slow 3D $\tau_{\text {ex }}$ (ranked eighth), though has the third-fastest $2 \mathrm{D} \tau_{\mathrm{ex}}$.

The exchange time estimated from surface values, especially at only a small number of longitudes, is clearly a poor predictor of true interhemispheric mixing in these models. The fact that the ranking of exchange time estimates is nearly unchanged from the $1 \mathrm{D}$ to the $2 \mathrm{D}$ case, but changes dramatically from the $2 \mathrm{D}$ case to the $3 \mathrm{D}$ case indicates that differences in vertical structure among the models dominate the differences in true interhemispheric exchange.

\subsection{Resolved transport}

In this Subsection, we examine some key features of the transport due to the resolved (nonparameterized) winds of the models.

4.2.1. Vertically integrated transport constraint and eddies. We consider the vertically integrated flux of $\mathrm{SF}_{6}$ as the simplest characterization of the resolved transport. The monthly and zonally averaged, vertically integrated transport equation for $C^{+}=C-C_{0}$, where $C_{0}$ is the spatially uniform background mass mixing ratio, can be written as

$\overline{\frac{\partial}{\partial t}\left[\left\langle C^{+}\right\rangle\right]}+\frac{\partial}{\partial y} \overline{\left[\left\langle v C^{+}\right\rangle\right]}=\left[\overline{S_{\text {err }}}\right]+\left[\overline{\left\langle P_{\mathrm{H}}\right\rangle}\right]$.

In (3), we use the notation $\langle X\rangle \equiv \int^{\mathrm{p}_{\mathrm{s}}} X \mathrm{~d} p / g$ for the vertical integral of $X$, define, $\partial X / \partial y \equiv \partial(X \cos \phi) / \partial(a \sin \phi), a$ is the radius of the earth, $P_{\mathrm{H}}$ represents the horizontal subgrid parameterized "tendencies", and

$S_{\text {eff }} \equiv S-\left\langle\partial C_{0} / \partial t\right\rangle=S-\frac{p_{\mathrm{s}}}{\left(p_{\mathrm{s}}\right)_{\mathrm{g}}}(S)_{\mathrm{g}} \approx S-(S)_{\mathrm{g}}$

is the effective source term for $C^{+}$, where $(\ldots)_{\mathrm{g}}$ denotes the global surface average. The global average $\left(S_{\text {eff }}\right)_{\mathrm{g}}$ vanishes, so that $C^{+}$is exactly conserved as must be the case since we removed $C_{0}$.

To quantify how much of the resolved transport is due to eddies, the time and zonally averaged horizontal tracer flux is usefully partitioned into its standard mean-motion, standing-eddy, and transient-eddy components as

$\left[\overline{v C^{+}}\right]=[\bar{v}]\left[\bar{C}^{+}\right]+\left[\bar{v}^{*} \bar{C}^{*}\right]+\left[\overline{v^{\prime} C^{+\prime}}\right]$,

where for some variable $X, \overline{X^{*}} \equiv \bar{X}-[\bar{X}]$, and $X^{\prime} \equiv X-\bar{X}$ are the deviations from the timeaveraged zonal and local temporal (monthly, here) average, respectively. This decomposition was done on pressure surfaces so that deviations from the means have a natural physical interpretation and do not correspond to the mere motion of a coordinate surface. We will consider here only the vertical integrals of the terms on the rhs of (4), which were necessarily also done in pressure coordinates with unphysical locations where $p>p_{\mathrm{s}}$ properly masked out (Boer, 1992). \{Except for interpolation errors, this ensures that the integrals of the right hand side of (4) sum to $\left[\overline{\left\langle v C^{+}\right\rangle}\right]$.

For ease of interpretation, note that for the vertically integrated fluxes it does not matter whether the full mixing ratio $C^{+}=C-C_{0}$ or its deviation, $C^{+}$, are used. For vertically integrated fluxes we therefore drop the + on $C$. The utility of splitting the mixing ratio into $C^{+}$and $C_{0}$ lies in the fact that we can interpret $\partial C_{0} / \partial t$ as an effective sink which balances the bulk of the divergence of $[\langle v C\rangle]$ in the southern hemisphere.

Given that $C^{+}$is in a statistically quasistationary state, $\overline{\partial C^{+} / \partial t}$ can to first order be neglected in (3) so that the net zonally and vertically integrated flux is approximately given by

$\cos \phi[\overline{\langle v C\rangle}] \approx a \int_{-\pi / 2}^{\phi}\left(\left[\overline{S_{\text {eff }}}\right]+\left[\overline{\left\langle P_{\mathrm{H}}\right\rangle}\right]\right) \mathrm{d}\left(\sin \phi^{\prime}\right)$.

Thus, as long as $P_{\mathrm{H}}$ is small, the total meridional flux is determined by the running integral of, $\left[\overline{S_{\text {eff }}}\right]$, or $\int^{y}\left[\overline{S_{\text {eff }}}\right] \mathrm{d} y^{\prime}$ for short hand. As such, the total flux is an important basic constraint on the 3-dimensional transport via (5), and contains some information about the importance of horizontal diffusion and the degree to which $\overline{\partial C^{+} / \partial t}$ is small. Otherwise, the highly constrained total flux carries little more information than what the specified sources are, so that the interest here lies in how the total flux partitions into contributions from different mechanisms, i.e., into mean-motion, and eddy fluxes.

The constraint (5) may be regarded as a continu- 
ous generalization of the 2-box model [cf. eqs (1) and (2)]. For $\phi=0$ (and multiplying by $2 \pi a$ ), the left-hand side of (5) is simply the rate of mass flow across the equator, while the right-hand side (for negligible $P_{\mathrm{H}}$ ) becomes $-\Delta S / 2$. This relates to the 2-box model, where the cross-equatorial flux is expressed as $\Delta M / \tau_{\mathrm{ex}}$. Equating this 2-box flux to the result from (5) gives $\tau_{\mathrm{ex}}=2 \Delta M / \Delta S$ precisely as in the 2-box formulation.

4.2.2. Model results and intercomparison. Fig. 10 shows the total vertically integrated meridional mass flux (across an entire latitude circle) and the terms of its monthly-mean transport partition averaged over the months of the intercomparison year. The curves are plotted versus $\sin (\phi)$, so that their slope is directly proportional to the flux divergence (positive/negative slope for con/ divergence). These annual averages render $\overline{\partial C^{+} / \partial t}$ negligible so that the total flux can be expected to obey the constraint (5) to good accuracy, provided $P_{\mathrm{H}}$ is small. Except for GISS, this is the case for all models in that they cluster reasonably close to the $\int^{y}\left[\overline{S_{\text {eff }}}\right] \mathrm{d} y^{\prime}$ curve. The significant departure from this curve for GISS indicates that its parameterized and resolved horizontal transport are of the same order of magnitude. The large parameterized horizontal transport of the GISS model is a well-known design feature which was added to compensate for inadequate interhemispheric mixing (Prather et al., 1987). The GISS model is consequently also distinguished from other models in terms of its mean-motion and eddy components. When the GISS model is run without the parameterized diffusive transport, it produces resolved fluxes that obey (5) as
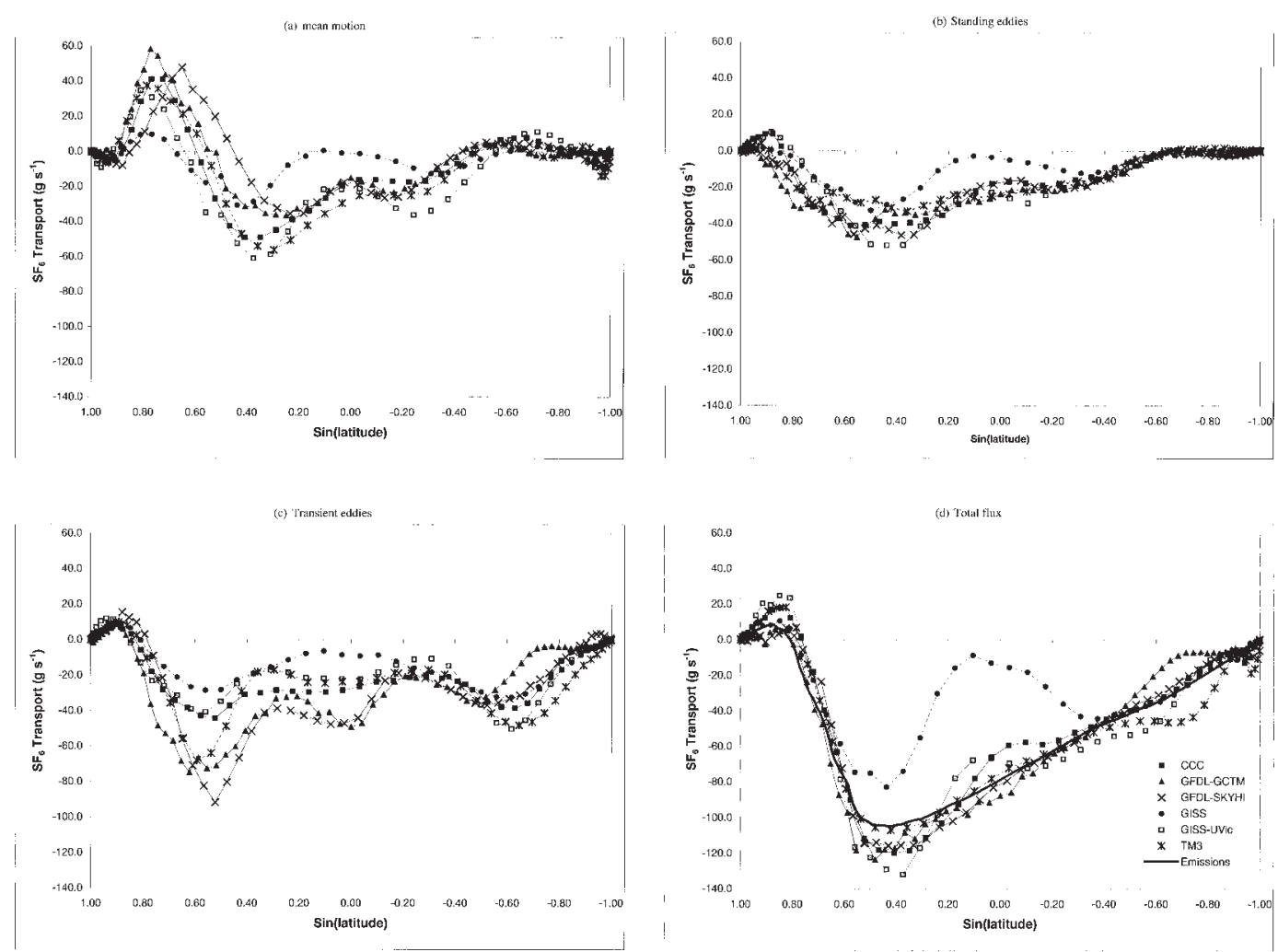

Fig. 10. Vertically integrated net mass flux across latitude circles decomposed as described in the text into contributions from the mean motion, standing eddies and transient eddies in addition to the total flux computed as their sum. The decomposition was computed from the monthly means and then averaged over the intercomparison year (Northward flux is positive).

Tellus 51B (1999), 2 
expected, but at the price of a north-south gradient of $\mathrm{SF}_{6}$ double that without diffusion (not shown).

The small departures of the other models from the $\int^{y}\left[\overline{S_{\text {eff }}}\right] \mathrm{d} y^{\prime}$ curve cannot necessarily be interpreted as physically meaningful because of unavoidable vertical interpolation error. The total vertically integrated flux was computed as the sum of the mean-motion and eddy terms, each of which were by necessity computed from data interpolated to pressure surfaces. Depending on the vertical resolution of the model, interpolation errors can be on the order of $\sim 10 \%$. For example, if the vertical integral of the total flux of the CCC model is computed on model surfaces, and thereby formally exact, it is nearly coincident with $\int^{y}\left[\overline{S_{\text {eff }}}\right] \mathrm{d} y^{\prime}$.

A central, though not a priori obvious, result displayed by Fig. 10, which holds for all models, is that the fluxes due to mean motion, standing, and transient eddies are all of the same order of magnitude in the northern hemisphere. In southern hemisphere mid-latitudes, a lack of east-west asymmetry, and weaker vertical gradients reduce the standing eddies and the mean-motion term, respectively, and the transient eddies dominate.

The vertically integrated mean-motion term, $\langle[\bar{v}][\bar{C}]\rangle$, (Fig. 10a) is a measure of the models' circulation and mixing-ratio climatology. Common to all models is enhanced southward (negative) subtropical mean-motion flux in both hemispheres. This enhancement results from the low-level convergence northward of the ITCZ, where $[\bar{C}]$ is large at low levels, and the uppertropospheric divergent outflow southward of the ICTZ, where $[\bar{C}]$ is large aloft. Differences in the mean-motion term point to differences in the modeled mass stream function and mean mixing ratio. For example, for the same mass stream function, weaker vertical gradients of mixing ratio result in a weaker mean-motion term, since $\langle[\bar{v}]\rangle=0$ to an excellent approximation. This effect may account for some of the differences between models, though the equatorward shift in the curve for SKYHI is due to that model's unusually latitudinally narrow circulation cells. (Air-mass flow diagnostics will be compared to observations in a future publication.)

All models (except GISS) show roughly the same structure in the standing-eddy flux (Fig. 10b), with relative maxima in the subtropics in both hemispheres. The standing-eddy fluxes show the least spread among models, possibly suggesting that much of the East-West structure in mixing ratio is simply determined by the source pattern (common to all models). TM3 has the lowest subtropical and tropical standing-eddy transport, which could either mean that its fields are more zonally symmetric, or less efficient in transporting because of unfavorable spatial phasing between $\bar{C}^{*}$ and $\bar{v}^{*}$. North of about $60^{\circ} \mathrm{N}(\sin \phi=0.87)$, the CCC and GISS-UVIC models have the strongest standing-eddy northward transport. At Northern latitudes tracer tends to be confined close to the surface in winter, so that the spread amongst models there might be due to inconsistencies in the ways in which terrain piercing pressure surfaces have been masked out.

For the transient eddy fluxes (Fig. 10c), all models show relative maxima at mid-latitudes in both hemispheres, while some models show in addition a relative maximum at the equator. The enhanced transient transport at mid latitudes $(\sin \phi=0.6)$ is attributable at least in part to the high variability associated with the mid-latitude jets. The largest spread between the models is seen in the transient eddies pointing to the difficulty in capturing temporal fluctuations in models of modest vertical resolution. Models with higher vertical resolution such as TM3 and GFDL have the strongest transient eddy transport.

\section{Discussion and conclusions}

\subsection{Model intercomparison and comparison to observations}

We find that the $\mathrm{SF}_{6}$ simulations are generally divided into those which reproduce the meridional gradient in the remote MBL but overestimate continental $\mathrm{SF}_{6}$ maxima and the west-east gradient as measured by the railroad transect (CCC, GFDL-GCTM, GFDL-SKYHI, and GISS-UVic), and those which underestimate the MBL gradient but match observations better at continental locations (CSU, GISS, and MUTM). The more "convective" models tend to systematically underestimate $\mathrm{SF}_{6}$ at most surface locations where measurements are available. The NIRE and TM3 models appear to overestimate both the meridional gradient in the MBL and also the zonal gradient across Eurasia. The ANU model underestimates $\mathrm{SF}_{6}$ relative to observations except in the immediate vicinity of emissions. 
Overestimation in source regions implies stronger meridional gradients in the zonal mean for TransCom 1, which suggests that "outlier" models (GFDL-GCTM, CSIRO9) that simulated very strong gradients for the fossil fuel experiment were probably unrealistic. In contrast to the results of TransCom 1 (Law et al., 1996), there was less spread in the simulated north-south tracer gradient in the remote MBL ( $\sim 50 \%$ vs. $\sim 100 \%$ for the fossil fuel experiment in TransCom 1).

\subsection{Mechanisms for differences among simulations}

Our results underline the importance of vertical transport, even for interhemispheric transport. Differences in the meridional gradient of $\mathrm{SF}_{6}$ at observing sites in the remote MBL among models cannot be explained solely in terms of differences in meridional transport or interhemispheric mixing. Rather, a combination of vertical and meridional transport is involved, with strong meridional gradients at the surface being associated with strong vertical gradients over the source regions. The differences among models are best explained in terms of differences in the intensity of subgrid-scale parameterized vertical transport rather than in terms of distinctions between CTMs and GCMs, or the use of analyzed wind observations rather than GCM simulated winds for the resolved transport. These differences may reflect differences in the thermodynamic stability of the troposphere in the "parent" models from which the transports are taken, or they may reflect differences in the methods used to calculate the transports among models.

Differences among models in the interhemispheric exchange time by up to a factor of two cannot be understood in terms of spatial distributions of tracer at the surface (Subsection 4.1), but are dominated by differences in vertical structure. Observed meridional gradients of tracers should be interpreted with caution, since a two-box mixing model based on surface observations can clearly produce qualitatively false results in which vertical mixing is misconstrued as interhemispheric transport.

The total vertically integrated meridional flux of $\mathrm{SF}_{6}$ due to resolved winds is constrained to balance the surface emissions, provided parameterized horizontal transport is small. To within unavoidable interpolation error, this constraint is obeyed by all models except GISS, which accom- plishes much of its meridional transport via subgrid-scale diffusion. In all cases, the meridional transport by the mean motion, standing eddies, and transient eddies are of the same order of magnitude. The least spread among models is seen in the standing-eddy flux, while the transient-eddy flux displays the largest spread.

\subsection{Recommended improvements to models and observing systems}

Our results underline the importance of subgridscale parameterized vertical transport, even for the interhemispheric transport of a long-lived passive tracer. Model development should focus on improvements to this aspect of the tracer transport rather than on improved numerical schemes for horizontal advection or the use of better analyzed wind products.

Unfortunately, the vertical distribution of atmospheric trace gases is much more difficult and expensive to measure in the atmosphere than is the horizontal spatial structure at the surface. Observational data collected at the surface may easily be misinterpreted in terms of meridional transport and interhemispheric mixing unless a better constraint is placed on vertical profiles in areas of elevated surface concentrations and on meridional gradients aloft. A series of regular vertical profiles of $\mathrm{SF}_{6}$ over western Europe and the northeastern United States would add considerable constraints to models. If such a program were combined with periodic meridional profiles in the middle to upper troposphere, it would be feasible to falsify one or the other of the two "families" of simulations presented here.

The TransCom $2 \mathrm{SF}_{6}$ experiment has produced a wealth of information on the participating models' resolved and parameterized transport processes (see Section 8), much of which still remains to be analyzed. Future analysis of these results will focus on understanding the interaction of the subgrid-scale tendencies with the resolved transport that produced the differences presented in this paper.

The use of tracer transport models for atmospheric inversion studies is a valuable tool that can add significant information about sources and sinks of atmospheric trace gases. Such calculations currently face considerable uncertainty due to differences in simulated transport, as outlined here 
and in other model intercomparison studies. A worthwhile future goal would be to quantify the uncertainty in carbon cycle inversion calculations arising from transport uncertainties, through an inversion intercomparison.

\section{Acknowledgements}

TransCom is a special project of the IGBP Global Analysis, Interpretation, and Modeling (GAIM) Project. Coordination of the activity was partially funded by the GAIM Office. Additional support for TransCom coordination was provided by the NASA EOS Interdisciplinary Science Program, under contract NAS5-97146. We thank Pieter Tans and Ed Dlugokencky, who provided the NOAA-CMDL flask data on $\mathrm{SF}_{6}$, and Dale Hurst, who provided the tall tower timeseries data. We are grateful to Sebastian Heimann for assistance in the analysis and graphical display of the time-series data. Computing support for the TM3 simulations has been provided by the Deutsches Klimarechenzentrum (DKRZ), Hamburg. R. Law and P. Rayner were supported by the Australian Government Cooperative Research Centres Programme. I. Y. Fung was supported by the NASA EOS-IDS program and the Canadian Climate Research Network. Jasmin John carried out the computations of the GISS and GISS-UVic models. Song-Miao Fan was supported by the NOAA Geophysical Fluid Dynamics Laboratory and the Office of Global Programs through the Carbon Modeling Consortium, and thanks Jerry Mahlman for his advice. The manuscript was substantially improved by the helpful comments of Mike Apps and an anonymous reviewer.

\section{Appendix A: Model Descriptions}

$A N U$

The ANU-CTM includes a stochastic Lagrangian advection scheme to move air parcels representing a known mass of tracer in air according to a monthly mean and variance wind field, derived from ECMWF data for the period 1980-1994, on a T42 latitude/longitude grid (Taylor, 1989). The ECMWF data has between seven and fifteen vertical levels depending on the year. The wind field includes a mean and time varying component. Conservation of tracer mass is accounted for by definition in the Lagrangian transport scheme so no mass fixer is required. The model surface layer is defined by the NCAR CCM3 boundary layer heights. Convection is based on a Tiedke scheme derived from the ECMWF model by Martin Heimann. For TransCom 2 the ECMWF wind fields representing the years 1988-1993 were employed in the model run.

CCC

The simulations submitted by the Canadian Centre for Climate Modelling and Analysis were performed with CCC GCMII (McFarlane et al., 1992, and references therein). CCC GCMII is a spectral model with triangular truncation at principle wave number 32 and 10 hybrid sigmapressure vertical levels with an upper boundary at $10 \mathrm{mb}$. The tracer advection was performed spectrally without any hole filling. While this does not ensure positive definiteness of the mixing ratio at all times, the very accurate spectral transport is a bonus and the occasional Gibbs overshoot is not an impediment for a purely passive tracer, such as $\mathrm{SF}_{6}$. Parameterizations of unresolved tracer transport parallel those used for moisture. In the vertical they consist of stability-dependent diffusion and a simple moist convective adjustment scheme. In the horizontal, a small amount of damping is applied spectrally to high wave numbers only. The transport of passive tracers in this model has recently been systematically analyzed in some detail (Holzer, 1999).

\section{CSU}

The Colorado State University (CSU) General Circulation Model (GCM) was derived from the UCLA GCM by D. Randall and colleagues. The model includes parameterizations of the effects of moist cumulus convection [Randall and Pan, 1993] and cloud microphysics (Fowler et al., 1996). A key feature of the model is its formulation in a modified sigma coordinate which is defined such that the top of the PBL is a coordinate surface (Suarez et al., 1983). The depth of the turbulent PBL is determined as a prognostic variable in the model using a method based on the turbulence kinetic energy equation (Randall et al., 
1992). Surface fluxes of momentum, energy, water, and carbon at land grid points are calculated on-line using the Simple Biosphere Model (SiB2, Sellers et al., 1996; Denning et al., 1996a).

Tracer transport includes large-scale advection and sub-grid scale vertical transport by penetrative cumulus convection, dry convective mixing, and boundary-layer turbulence and entrainment (Denning et al., 1995, 1996b). Cumulus convection originates in multiple model layers, and transports tracer in a penetrative manner to any higher layer in the troposphere. Tracer advection is calculated by a second-order, centered-in-space, leapfrog-intime scheme. At the PBL top, a first-order upstream scheme is applied separately for turbulent entrainment and loss of tracer mass from the PBL due to cumulus mass flux. After each 10 leapfrog timesteps, a Matsuno step is performed to suppress the computational mode. TransCom $\mathrm{SF}_{6}$ experiments were integrated on a $4^{\circ} \times 5^{\circ}$ grid with 17 levels, at a time step of $5 \mathrm{~min}$.

\section{GFDL-GCTM}

The GCTM is driven by 6-hour time-averaged winds and a consistent total column precipitation field that was generated by a parent general circulation model (GCM) integrated for 1 year without diurnal insolation [see Section 2. of Mahlman and Moxim (1978) for details]. Therefore, the GCTM can not realistically simulate atmospheric fluctuations with periods shorter than $6 \mathrm{~h}$ or examine interannual variability. Both the parent GCM and the GCTM have the same resolution, a horizontal grid size of $\sim 265 \mathrm{~km}$, and 11 vertical levels at standard pressures of 990, 940, $835,685,500,315,190,110,65,38$, and $10 \mathrm{mb}$. The GCTM includes parameterizations designed to incorporate the effects of horizontal sub-grid scale transport, as well as vertical mixing by dry and moist convection throughout the troposphere and a vertical wind-shear dependent turbulent transport in the boundary layer (for details see Appendix A in Levy et al. (1982), and Section 2 in Kasibhatla et al. (1993)).

\section{GFDL-SKYHI}

The GFDL SKYHI model has a long history of development, and has a variety of options for grid size and advection scheme (Mahlman et al.,
1984; Mahlman et al., 1994). Climatology of the SKYHI model is described in detail in Hamilton et al. (1995).

The present standard version has 40 vertical layers, with the lowest thirteen layers centered at $0.08,0.27,0.74,1.4,2.2,3.1,4.1,5.2,6.5,7.8,9.1$, 10.5 , and $12.0 \mathrm{~km}$ altitude over the sea, and with the lowest 10 levels following surface topography. It has a horizontal grid size of $3^{\circ}$ latitude by $3.6^{\circ}$ longitude. The model uses specified values of sea surface temperature but calculates land temperature prognostically. The model calculates the moisture content prognostically.

The SKYHI model calculates radiative transfer and the absorption and emission of radiation by $\mathrm{O}_{3}, \mathrm{H}_{2} \mathrm{O}$ and $\mathrm{CO}_{2}$ molecules, and clouds. The radiation was calculated for time interval of $4 \mathrm{~h}$ in the $\mathrm{SF}_{6}$ experiment. Ozone and cloud distribution and ice-free surface albedo are prescribed.

Surface exchanges of heat, moisture, and momentum are parameterized, based on the Monin-Obhukov similarity theory, with bulk aerodynamic formulas. Sea surface roughness is calculated from wind stress while land roughness is a constant specified value. Parameterization of subgrid-scale transports uses horizontal diffusivity that is proportional to the magnitude of the horizontal velocity deformation, and uses vertical diffusivity that is proportional to the magnitude of the vertical wind shear and is a function of the moist bulk Richardson number. In a recent modification of the SKYHI model, maximum vertical diffusivity is calculated for chemical tracers that is allowed by the centered differencing scheme without numerical instability, and is used to represent the rapid vertical mixing of $\mathrm{SF}_{6}$ under unstable conditions (J. Mahlman, personal communication).

\section{GISS}

The GISS tracer model was developed in the late 1970's and early 1980's, and its design reflected the computational capabilities of that era. The circulation commonly used is derived from the 1984 version of the GISS GCM (Hansen et al., 1983 ), run at a resolution of $4^{\circ}$ latitude $\times 5^{\circ}$ longitude with 9 sigma levels in the vertical. The horizontal mass fluxes from the GCM were accumulated over $4 \mathrm{~h}$ periods and archived. Advection is by the linear upstream scheme of Russell and 
Lerner (1981). From the GCM, the total number of mixing events in a month between two vertical layers is recorded for moist and dry convection. The monthly convective frequency is then translated into a fraction of the gridbox air mass that mixes every time step $(4 \mathrm{~h})$. The approach was necessitated by computer memory limitations and was adopted to reproduce on-line GCM simulations of tracer concentrations at monthly means, but not at higher frequencies. To match the interhemispheric transport time for CFCs, Prather et al. (1987) introduced a sub-grid scale horizontal diffusion based on the depth of moist convection. The version of the GISS tracer model used for TransCom 1 employs the same GCM circulation statistics at $4 \times 5$ resolution, but the mass fluxes were aggregated to $8 \times 10$. In this study, the tracer model was run at the GCM resolution of $4 \times 5$.

\section{GISS-UVic}

The GISS-UVic tracer model is derived from the 1996 version of the GISS GCM (Hansen et al., 1996). The resolution of the GCM and the tracer model is $4 \times 5$ with 9 sigma levels in the vertical. The 1996 version of the GCM has many improved treatments of atmospheric physics compared to the 1984 version. Important for tracers is the parameterization of moist convection (DelGenio and Yao, 1993), clouds (DelGenio et al., 1996), and the planetary boundary layer (Hartke and Rind, 1997). Moist convection (DelGenio and Yao, 1993) is linked to mass flux closure as well as stability of the column; convective downdrafts, and mesoscale cirrus anvils are included. From the GCM, large scale fields of horizontal mass fluxes are archived every hour for calculation of large scale advection in the tracer model. The linear upstream scheme of Russell and Lerner (1981) is used. At every GCM physics time step ( $1 \mathrm{~h}$ for moist and dry convection), the tracer model duplicates exactly the GCM calculation of mixing by moist convection and dry convection. For moist convection, this is achieved by archiving the $3 \mathrm{D}$ fields of temperature and humidity just before the hourly call to moist convection in the GCM, and repeating the GCM moist convection subroutine in the tracer code, which then mixes, entrains and detrains tracers in addition to temperature and humidity according to the conditions captured in the temperature and humidity profiles.
For dry convection, the height of planetary boundary layer is archived every hour. No explicit horizontal or vertical diffusion is included.

\section{MUTM}

The Melbourne University Tracer Model (MUTM), described by Law et al. (1992), is an offline transport model derived from the Melbourne University General Circulation Model (GCM). It is a spectral model with rhomboidal 21 wave resolution and 9 levels. The transport is forced by daily winds from a control run of the Melbourne University GCM. There is no diurnal cycle but tests using $\mathrm{CO}_{2}$ have shown that transport is similar for 6 hourly winds with a diurnal cycle. Vertical diffusion is parameterized using the same mixing length scheme as used in the GCM for moisture. Convective transport is parameterized based on daily convection statistics from the GCM.

\section{NIRE}

NIRE-CTM-96 is a modified version of NIRECTM-93 (Taguchi, 1996). Major modifications are vertical coordinates from sigma to pressuresigma mixture and explicit use of a tropopause diagnosed from ECMWF temperature profiles. Turnover time of the stratosphere in NIRECTM-96 is 1.5 years which is significantly longer than the 0.5 years of NIRE-CTM-93.

\section{$T M 2$}

The Tracer Model version 2 is modified from TM1, which was adapted by Heimann and Keeling (1989) from the GISS model, for use with analyzed winds. TM2 is an offline CTM which differs from TM1 in its subgrid-scale parameterized vertical transport. TM2 simulates vertical transport by stability-dependent vertical diffusion following Louis (1979), and by cumulus convection following Tiedke (1989). Advection by the mean flow is calculated using the slopes scheme (Russell and Lerner, 1981). The experiments described in the present paper were performed on a horizontal grid of $7.5^{\circ} \times 7.5^{\circ}$ (latitude-longitude), with 9 levels in the vertical, and a time step of $3 \mathrm{~h}$. Resolved transport was forced with winds specified from ECMWF analyses for 1993, which were updated every $12 \mathrm{~h}$. 
Table 5. Required output: monthly mean diagnostic maps

\begin{tabular}{|c|c|}
\hline Diagnostic & Descrption \\
\hline$\chi_{\mathrm{sfc}}$ & mole fraction of $\mathrm{SF}_{6}$ at surface or in lowest layer (pptv) \\
\hline $\int_{p_{1}}^{p_{2}} C^{+} \mathrm{d} p / g$ & $\begin{array}{l}\text { mean mass per unit area of } \mathrm{SF}_{6} \text { between } p_{1} \text { and } p_{2}\left(\mathrm{~kg} \mathrm{~m}^{-2}\right) \\
3 \mathrm{maps} \text { ( }(\mathrm{sfc} \text { to } 700 \mathrm{mb}),(700 \text { to } 250 \mathrm{mb}),(350 \mathrm{mb} \text { to top })\end{array}$ \\
\hline $\int_{p_{1}}^{p_{2}} u C^{+} \mathrm{d} p / g$ & $\begin{array}{l}\text { resolved zonal flux of } \mathrm{SF}_{6} \text { between } p_{1} \text { and } p_{2}\left(\mathrm{~kg} \mathrm{~m}^{-1} \mathrm{~s}^{-1}\right) \\
3 \text { maps: (sfc to } 700 \mathrm{mb}),(700 \text { to } 350 \mathrm{mb}),(350 \mathrm{mb} \text { to top })\end{array}$ \\
\hline $\int_{p_{1}}^{p_{2}} v C^{+} \mathrm{d} p / g$ & $\begin{array}{l}\text { resolved meridional flux of } \mathrm{SF}_{6} \text { between } p_{1} \text { and } p_{2}\left(\mathrm{~kg} \mathrm{~m}^{-1} \mathrm{~s}^{-1}\right) \\
3 \text { maps: (sfc to } 700 \mathrm{mb}),(700 \text { to } 350 \mathrm{mb}),(350 \mathrm{mb} \text { to top })\end{array}$ \\
\hline$\beta \omega C^{+} g$ & $\begin{array}{l}\text { resolved vertical (downward) flux of } \mathrm{SF}_{6}\left(\mathrm{~kg} \mathrm{~m}^{-2} \mathrm{~s}^{-1}\right) \\
2 \text { maps: at } 700 \mathrm{mb} \text { and } 350 \mathrm{mb}\end{array}$ \\
\hline $\int_{p_{1}}^{p_{2}} u \mathrm{~d} p / g$ & $\begin{array}{l}\text { zonal mass flux of air between } p_{1} \text { and } p_{2}\left(\mathrm{~kg} \mathrm{~m}^{-1} \mathrm{~s}^{-1}\right) \\
3 \text { maps: (sfc to } 700 \mathrm{mb}),(700 \text { to } 350 \mathrm{mb}),(350 \mathrm{mb} \text { to top })\end{array}$ \\
\hline $\int_{p_{1}}^{p_{2}} v \mathrm{~d} p / g$ & $\begin{array}{l}\text { meridional mass flux of air between } p_{1} \text { and } p_{2}\left(\mathrm{~kg} \mathrm{~m}^{-1} \mathrm{~s}^{-1}\right) \\
3 \mathrm{maps} \text { ( } \mathrm{sfc} \text { to } 700 \mathrm{mb}),(700 \text { to } 350 \mathrm{mb}),(350 \mathrm{mb} \text { to top })\end{array}$ \\
\hline$\beta \omega / g$ & $\begin{array}{l}\text { vertical (downward) mass flux of air }\left(\mathrm{kg} \mathrm{m}^{-2} \mathrm{~s}^{-1}\right) \\
2 \text { maps: at } 700 \mathrm{mb} \text { and } 350 \mathrm{mb}\end{array}$ \\
\hline$\frac{1}{g} \int_{p_{1}}^{p_{2}} \frac{\partial^{2} C}{\partial y^{2}} \mathrm{~d} p$ & $\begin{array}{l}\mathrm{SF}_{6} \text { tendency due to meridional diffusion }\left(\mathrm{kg} \mathrm{m}^{-2} \mathrm{~s}^{-1}\right) \\
3 \text { maps: (sfc to } 700 \mathrm{mb}),(700 \text { to } 350 \mathrm{mb}),(350 \mathrm{mb} \text { to top })\end{array}$ \\
\hline$\frac{1}{g} \int_{p_{1}}^{p_{2}} k_{z} \frac{\partial^{2} C}{\partial z^{2}} \mathrm{~d} p$ & $\begin{array}{l}\mathrm{SF}_{6} \text { tendency due to vertical diffusion }\left(\mathrm{kg} \mathrm{m}^{-2} \mathrm{~s}^{-1}\right) \\
3 \text { maps: (sfc to } 700 \mathrm{mb}),(700 \text { to } 350 \mathrm{mb}),(350 \mathrm{mb} \text { to top })\end{array}$ \\
\hline $\int_{p_{1}}^{p_{2}}\left(\frac{\partial C}{\partial t_{\text {cumulus }}}\right) \frac{\mathrm{d} p}{g}$ & $\begin{array}{l}\mathrm{SF}_{6} \text { tendency due to cumulus convection }\left(\mathrm{kg} \mathrm{m}^{-2} \mathrm{~s}^{-1}\right) \\
3 \text { maps: (sfc to } 700 \mathrm{mb}),(700 \text { to } 350 \mathrm{mb}),(350 \mathrm{mb} \text { to top })\end{array}$ \\
\hline $\int_{p_{1}}^{p_{2}}\left(\frac{\partial C}{\partial t_{\mathrm{dry}}}\right) \frac{\mathrm{d} p}{g}$ & $\begin{array}{l}\mathrm{SF}_{6} \text { tendency due to dry convection }\left(\mathrm{kg} \mathrm{m}^{-2} \mathrm{~s}^{-1}\right) \\
3 \text { maps: (sfc to } 700 \mathrm{mb}),(700 \text { to } 350 \mathrm{mb}),(350 \mathrm{mb} \text { to top) }\end{array}$ \\
\hline $\int_{p_{1}}^{p_{2}}\left(\frac{\partial C}{\partial t_{\text {subgrid }}}\right) \frac{\mathrm{d} p}{g}$ & $\begin{array}{l}\text { all vertical sub-grid scale processes }\left(\mathrm{kg} \mathrm{m}^{-2} \mathrm{~s}^{-1}\right) \\
3 \text { maps: ( } \mathrm{sfc} \text { to } 700 \mathrm{mb}),(700 \text { to } 350 \mathrm{mb}),(350 \mathrm{mb} \text { to top) }\end{array}$ \\
\hline
\end{tabular}

TM3

The Tracer Model version 3 is the successor of the atmospheric transport model TM2 (Heimann, 1995). It computes in an off-line mode the transport of a tracer based on the fields from 3-dimensional meteorological analyses or from the output of an atmospheric general circulation model. The version used in the TransCom 2 experiments has a horizontal resolution of $5^{\circ}$ longitude by $3.8^{\circ}$ latitude and a hybrid (sigmapressure) vertical coordinate with 19 layers from the surface to the top of the atmosphere $(100 \mathrm{hPa})$.
The meteorology used in the $\mathrm{SF}_{6}$ simulations is from a T42 control run of the ECHAM3 climate model, stored at a temporal resolution of $6 \mathrm{~h}$. Resolved transport is computed numerically with the slopes scheme (Russel and Lerner, (1981). Subgrid scale transport in the vertical is computed by stability dependent vertical diffusion (Louis, 1979) and cloud convection (Tiedke, 1989). Both schemes are identical to the schemes employed in the "parent" climate GCM. There is no horizontal diffusion. Diurnal cycles are only marginally resolved in the present version due to the coarse temporal resolution of the input fields. 
Table 6. Required output: monthly mean zonal mean diagnostic cross-sections on pressure surfaces

\begin{tabular}{|c|c|}
\hline Diagnostic & Descrption \\
\hline$[\bar{\chi}]^{R}$ & mole (volume) fraction of $\mathrm{SF}_{6}$ (pptv) \\
\hline$[\bar{v}]^{R}$ & meridional velocity component $\left(\mathrm{m} \mathrm{s}^{-1}\right)$ \\
\hline$\left[\overline{v C^{+}}\right]^{R}$ & meridional mass flux of $\mathrm{SF}_{6}\left(\mathrm{~m} \mathrm{~s}^{-1}\right)$ \\
\hline$\left[k_{y} \frac{\overline{\partial^{2} C}}{\partial y^{2}}\right]^{R}$ & $\mathrm{SF}_{6}$ tendency due to meridional diffusion $\left(\mathrm{kg} \mathrm{kg}^{-1} \mathrm{~s}^{-1}\right)$ \\
\hline$\left[k_{z} \frac{\overline{\partial^{2} C}}{\partial z^{2}}\right]^{R}$ & $\mathrm{SF}_{6}$ tendency due to vertical diffusion $\left(\mathrm{kg} \mathrm{kg}^{-1} \mathrm{~s}^{-1}\right)$ \\
\hline$\left[\frac{\overline{\partial C}}{\partial t_{\text {cumulus }}}\right]^{R}$ & $\mathrm{SF}_{6}$ tendency due to cumulus convection $\left(\mathrm{kg} \mathrm{kg}^{-1} \mathrm{~s}^{-1}\right)$ \\
\hline$\left[\frac{\overline{\partial C}}{\partial t_{\mathrm{dry}}}\right]^{R}$ & $\mathrm{SF}_{6}$ tendency due to dry convection $\left(\mathrm{kg} \mathrm{kg}^{-1} \mathrm{~s}^{-1}\right)$ \\
\hline$\left[\frac{\overline{\partial C}}{\partial t_{\text {subgrid }}}\right]^{R}$ & tendency due to all sub-grid scale processes $\left(\mathrm{kg} \mathrm{kg}^{-1} \mathrm{~s}^{-1}\right)$ \\
\hline$[\bar{\beta}]$ & zonal mean terrain mask (see appendix) \\
\hline
\end{tabular}

Table 7. Required output: monthly mean zonal mean meridional profiles of decomposed transport components

\begin{tabular}{lc}
\hline Diagnostic & Descrption \\
\hline $\int_{p_{1}}^{p_{2}}[\bar{\beta}][\bar{v}]^{R}[\bar{C}]^{R} \mathrm{~d} p / g$ & transport by the mean circulation $\left(\mathrm{kg} \mathrm{m}^{-1} \mathrm{~s}^{-1}\right)$ \\
$\int_{p_{1}}^{p_{2}}[\bar{\beta}]\left[\overline{v^{\prime} C^{*}}\right]^{R} \mathrm{~d} p / g$ & transport by the stationary eddies $\left(\mathrm{kg} \mathrm{m}^{-1} \mathrm{~s}^{-1}\right)$ \\
$\int_{p_{1}}^{p_{2}}[\bar{\beta}]\left[\overline{v^{\prime} C^{\prime}}\right]^{R} \mathrm{~d} p / g$ & transport by the transient circulation $\left(\mathrm{kg} \mathrm{m}^{-1} \mathrm{~s}^{-1}\right)$ \\
\hline
\end{tabular}

\section{Appendix B: Required diagnostics}

Each group provided 12 maps (corresponding to monthly means for each month in 1993) of $\mathrm{SF}_{6}$ mole fraction at the surface and 12 transport diagnostics (Table 5). Transport diagnostics were integrated over three vertical slabs (low-level, defined as surface to $700 \mathrm{hPa}$; mid-level, defined as $700 \mathrm{hPa}$ to $350 \mathrm{hPa}$; and upper-level, defined as $350 \mathrm{hPa}$ to the top of the model). Interpolation to pressure levels was performed at a high sam- pling rate (every $6 \mathrm{~h}$ or more). Monthly averages were then computed for the full diagnostics and archived as zonal averages (Table 6) or maps of integrals over pressure slabs. Care was taken to exclude unphysical locations where terrain intersected given pressure surfaces (Boer, 1982). Recognizing the importance of meridional transport in the $\mathrm{SF}_{6}$ problem (especially as it relates to the simulation of the interhemispheric gradient of $\mathrm{CO}_{2}$ ), the resolved meridional flux was decomposed into components related to the mean 
motion, standing eddies, and transient eddies (Table 7). Meridional profiles of zonal mean transport by each of these processes were computed for each vertical slab in each model for each month of 1993. Finally, hourly time series were saved for 20 locations where observational data are available.

\section{REFERENCES}

Boer, G. J., 1982. Diagnostic equations in isobaric coordinates. Mon. Weather Rev. 110, 1801-1820.

Bousquet, P., Ciais, P., Monfray, P., Balkanski, Y., Ramonet, M. and Tans, P. 1996. Influence of two atmospheric transport models on inferring sources and sinks of atmospheric $\mathrm{CO}_{2}$. Tellus 48B, 568-582.

Ciais, P., Tans, P. P., Trolier, M., White, J. W. C. and Francey, R. J. 1995. A large northern hemisphere terrestrial $\mathrm{CO}_{2}$ sink indicated by the ${ }^{13} \mathrm{C} /{ }^{12} \mathrm{C}$ ratio of atmospheric $\mathrm{CO}_{2}$. Science 269, 1098-1102.

Crutzen, P. J., Elansky, N. F., Hahn, M., Golitsyn, G. S., Brenninkmeijer, C. A. M., Scharffe, D. H., Berlikov, I. B., Maiss, M., Bergamaschi, P., Roeckmann, T., Grisenko, A. M. and Sevostyanov, V. M. 1998. Trace gas measurements between Moscow and Vladivostok using the Trans-Siberian Railroad, J. Atmos. Chem 29, 179-194.

Czeplak, G. and C. Junge, 1974: Studies of interhemispheric exchange in the troposphere by a diffusion model. Adv. Geophys. 18B, 57-72.

DelGenio, A. D. and M.-S. Yao (1993): Efficient cumulus parameterization for long-term climate studies: The GISS scheme. In Representation of cumulus convection in numerical models (K. A. Emanuel and D. A Raumopnd, eds.). AMS Meteor, Monograph 24, no. 46 pp. 181-184. American Meteorological Society.

DelGenio, A. D., M.-S. Yao, W. Kovari and K. K.-W. Lo (1996): A prognostic cloud water parameterization for global climate models. J. Clim. 9, 270-304.

Denning, A. S., Fung, I. Y., and Randall, D. A. 1995. Latitudinal gradient of atmospheric $\mathrm{CO}_{2}$ due to seasonal exchange with land biota. Nature 376, 240-243.

Denning, A. S., J. G. Collatz, C. Zhang, D. A. Randall, J. A. Berry, P. J. Sellers, G. D. Colello and D. A. Dazlich, 1996a. Simulations of terrestrial carbon metabolism and atmospheric $\mathrm{CO}_{2}$ in a general circulation model. Part 1: Surface carbon fluxes. Tellus 48B, 521-542.

Denning, A. S., Randall, D. A., Collatz, G. J., and Sellers, P. J. 1996b. Simulations of terrestrial carbon metabolism and atmospheric $\mathrm{CO}_{2}$ in a general circulation model. Part 2: Spatial and temporal variations of atmospheric $\mathrm{CO}_{2}$. Tellus 48B, 543-567.

Enting, I. G., Trudinger, C. M., and Francey, R. J. 1995. A synthesis inversion of the concentration and $\delta^{13} \mathrm{C}$ of atmospheric $\mathrm{CO}_{2}$. Tellus 47B, 35-52.

Feichter, J. and Crutzen, P. J. 1990. Parameterization of vertical tracer transport due to deep convection and its evaluation with ${ }^{222}$ Radon measurements. Tellus 42B, 100-117.
Fowler, L. A., Randall, D. A. and Rutledge, S. A., 1996. Liquid and ice cloud microphysics in the CSU General Circulation Model. Part I: Model description and simulated microphysical processes. J. Clim 9, 489-529.

Fung, I., Prentice, K., Matthews, E., Lerner, J. and Russell, G. 1983. Three-dimensional tracer model study of atmospheric $\mathrm{CO}_{2}$ : Response to seasonal exchanges with the terrestrial biosphere. J. Geophys. Res. 88, 1281-1294.

Geller, L. S., Elkins, J. W., Lobert, J. M., Clarke, A. D., Hurst, D. F., Butler, J. H. and Myers, R. C. 1997. Tropospheric $\mathrm{SF}_{6}$ : Observed latitudinal distribution and trends, derived emissions and interhemispheric exchange time. Geophys. Res. Lett. 24, 675-678.

Hamilton, K., Wilson, R. J., Mahlman, J. D., and Umscheid, L. J. 1995. Climatology of the SKYHI troposphere-stratosphere-mesosphere general circulation model. J. Atmos. Sci. 52, 5-43,

Hansen, J., Russell, G., Rind, D., Stone, P., Lacis, A., Lebedeff, S., Ruedy, R. and Travis, L. (1983). Efficient three-dimensional global models for climate studies: Models I and II. Mon. Wea. Rev. 111, 609-662.

Hansen, J., Sato, M., Ruedy, R., Lacis, A., Asamoth, K., Borenstein, S., Brown, E., Cairns, B., Caliri, G., Campbell, M., Curran, B., de Castro, S., Druyan, L., Fox, M., Johnson, C., Lerner, J., McCormick, M. P., Miller, R., Minnis, P., Morrison A., Pandolfo, L., Ramberran, I., Zaucker, F., Robinson, M., Ruseell, P., Shah, K., Stone, P., Tegen, I., Thomason, L., Wilder, J. and Wilson, H. (1996). A Pinatubo climate modeling investigation. In The Mount Pinatubo eruption effects on the atmosphere and climate (G. Fiocco, D. Fua and G. Visconti. eds.) NASO ASI Series, vol. I, 42, pp. 233-272. Springer-Verlag, Heidelberg, Germany.

Harnisch, J., Borchers, R., Fabian, P. and Maiss, M. 1996. Tropospheric trends of $\mathrm{CF}_{4}$ and $\mathrm{C}_{2} \mathrm{~F}_{6}$ since 1982 derived from $\mathrm{SF}_{6}$ dated stratospheric air. Geophys. Res. Lett. 23, 1099.

Hartke, G. J. and D. Rind (1997). Improved surface and boundary layer models for the Goddard Institute for Space Studies general circulation model. J. Geophys. Res. 102, 16407-16442.

Hartley, D., Williamson, D. L., Rasch, P. J. and Prinn, R., 1994. Examination of tracer transport in the NCAR CCM2 by comparison of $\mathrm{CFCl}_{3}$ simulations with ALE/GAGE observations. J. Geophys. Res. 99, 12885-12896.

Heimann, M., Keeling, C. D. and Fung, I. Y. 1986. Simulating the atmospheric carbon dioxide distribution with a three-dimensional tracer model. In: The

Tellus 51B (1999), 2 
changing carbon cycle: a global analysis, (eds Trabalka, J. R. and Reichle, D. E.). Springer-Verlag, New York, $16-49$.

Heimann, M. and Keeling, C. D. 1989. A threedimensional model of atmospheric $\mathrm{CO}_{2}$ transport based on observed winds: 2. Model description and simulated tracer experiments. In: Aspects of climate variability in the Pacific and Western Americas (ed. Peterson, D. H.). Geophysical Monograph 55, American Geophysical Union, Washington, DC, 237-275.

Heimann, M. 1995. The TM2 Tracer Model, Model Description and User Manual. Technical Report No. 10, ISSN 0940-9327, Deutsches Klimarechenzentrum, Hamburg, $47 \mathrm{pp}$

Holzer, M., 1999. Analysis of passive tracer transport as modelled by an atmospheric general circulation model. Jour. Clim., in press.

Hurst, D. F., Bakwin, P. S., Myers, R. C. and Elkins, J. W. 1997. Behavior of trace gas mixing ratios on a very tall tower in North Carolina. J. Geophys. Res 102, 8825-8835.

Jacob, D. J., Prather, M. J., Wofsy, S. C. and McElroy, M. B. 1987: Atmospheric distribution of ${ }^{85} \mathrm{Kr}$ simulated with a general circulation model. J. Geophys. Res. 92, 6614-6626.

Jacob, D. J. and Prather, M. J., 1990. Radon-222 as a test of boundary-layer convection in a general circulation model. Tellus 42B, 118-134.

Jacob, D. J., Prather, M. J., Rasch, P. J., Shia, R.-L., Balkanski, Y. J., Beagley, S. R., Bergmann, D. J., Blackshear, M. B., Chiba, M., Chipperfield, J. d G., Dignon, J. E., Feichter, J., Genthon, C., Grose, W. L., Khasibatla, P. S., Kohler, I., Kritz, M., Law, K., Penner, J. E., Ramonet, M., Reeves, C. E., Rotman, D. A., Stockwell, D. Z., van Velthoven, P. F. J., Verver, G., Wild, O., Yang, H. and Zimmerman, P. 1997. Evaluation and intercomparison of global atmospheric transport models using ${ }^{222} \mathrm{Rn}$ and other short-lived tracers. J. Geophys. Res. 102, 5953-5970.

Kasibhatla, P. S., Levy II, H. and Moxim, W. J., 1993. Global $\mathrm{NO}_{x}, \mathrm{HNO}_{3}, \mathrm{PAN}$ and $\mathrm{NO}$ distributions from fossil-fuel combustion emissions: A model study, J. Geophys. Res. 98, 7165-7180

Law, R. M., Simmonds, L. and Budd, A. 1992. Application of an atmospheric tracer model to the high southern latitudes. Tellus 44B, 358-370,

Law, R. M., Rayner, P. J., Denning, A. S., Erickson, D., Heimann, M., Piper, S. C., Ramonet, M., Taguchi, S., Taylor, J. A., Trudinger, C. M. and Watterson, I. G. 1996. Variations in modelled atmospheric transport of carbon dioxide and the consequences for $\mathrm{CO}_{2}$ inversions Global Biogeochem. Cycles 10, 783-796.

Levin, I. and Hesshaimer, V. 1996. Refining of atmospheric transport model entries by the globally observed passive tracer distributions of ${ }^{85} \mathrm{Kr}$ and sulfur hexafluoride $\left(\mathrm{SF}_{6}\right)$. J. Geophys. Res. 101, 16745-16755.

Levy II, H, Mahlman, J. D. and Moxim, W. J. 1982. Tropospheric $\mathrm{N}_{2} \mathrm{O}$ variability. J. Geophys. Res. 87, 3061-3080.
Levy II, H. and W.J. Moxim, Fate of US and Canadian combustion nitrogen emissions. Nature 328, 414-416, 1987.

Louis, J. F., 1979. A parametric model of vertical eddy fluxes in the atmosphere. Boundary Layer Meteorol. 17, 187-202.

Mahlman, J. D., and Moxim, W. J. 1978. Tracer simulation using a global general circulation model: results from a midlatitude instantaneous source experiment, J. of the Atmos. Sci. 35, 1340-1374,

Mahlman, J. D. and L. J. Umscheid, 1984. Dynamics of the middle atmosphere: Successes and problems of the GFDL "SKYHI" general circulation models. In: Dynamics of the Middle Atmosphere (eds Holton, J. R. and Matsuno, T.). Terra Scientific, pp. 501-525,

Mahlman, J. D., Pinto, J. P. and Umscheid, L. J. 1994. Transport, radiative, and dynamical effects of the Antarctic ozone hole: A GFDL "SKYHI" model experiment. J. Atmos. Sci. 51, 489-508

Mahowald, N. M., Rasch, P. J. and Prinn, R. G. 1995. Cumulus parameterizations in chemical transport models. J. Geophys. Res. 100, 26173-16190.

Maiss, M. and Levin, I. 1994. Global increase of $\mathrm{SF}_{6}$ observed in the atmosphere. Geophys. Res. Lett. 21, 569-572.

Maiss, M., Steele, L. P., Francey, R. J., Fraser, P. J., Langenfelds, R. L., Trivett, N. B. A. and Levin, I. 1996. Sulfur hexafluoride - a powerful new atmospheric tracer. Atmos. Environ. 30, 1621-1629.

McFarlane, N. A., Boer, G. J., Blanchet, J. P. and Lazare, M. 1992. The Canadian Climate Centre second generation general circulation model and its equilibrium climate. J. Clim. 5, 1013-1044.

Patra, P. K., Lal, S., Subbaraya, B. H., Jackman, C. H. and Rajaratnam, P. 1997. Observed vertical profile of sulfur hexafluoride $\left(\mathrm{SF}_{6}\right)$ and its atmospheric applications. J. Geophys. Res. 102, 8855-8859.

Plumb, R. A. and D. D. McConalogue, 1988: On the meridional structure of long-lived tropospheric constituents. J. Geophys. Res. 93, 15897-15913.

Prather, M., McElroy, M., Wofsy, S., Russel, G. and Rind, D. 1987. Chemistry of the global troposphere: Fluorocarbons as tracers of air motion. J. Geophys. Res. 92, 6579-6613.

Pyle, J. and Prather, M. (eds.) 1996. Global tracer transport models. Report of a Scientific Symposium, World Climate Research Programme, Report No. 24. 186 pp.

Randall, D. A., Shao, Q. and Moeng, C.-H. 1992. A second-order bulk boundary-layer model. J. Atmos. Sci. 49, 1903-1923.

Randall, D. A. and Pan, D.-M., 1993. Implementation of the Arakawa-Schubert parameterization with a prognostic closure. In: The Representation of Cumulus Convection in Numerical Models (eds Emanuel, K. and Raymond, D.). American Meteorological Society, Boston, 137-144.

Randall, D. R., Sellers, P. J., Berry, J. A., Dazlich, D. A., Zhang, C., Collatz, J. A., Denning, A. S., Los, S. O., Field, C. B., Fung, I., Justice, C. O. and Tucker, 
C. J. 1996. A revised land-surface parameterization (SiB2) for GCMs. Part 3: The greening of the Colorado State University General Circulation Model. J. Clim. 9, 738-763.

Ravishankara, A. R., Solomon, S., Turnispeed, A. A. and Warren, R. F., 1993. Atmospheric lifetimes of longlived halogenated species. Science 259, 194-199.

Rayner, P. J. and Law, R. M. 1995. A comparison of modelled responses to prescribed $\mathrm{CO}_{2}$ sources. CSIRO Division of Atmospheric Research Technical Paper No. 36. 84 pp.

Russell, G. and Lerner, J. (1981). A new finite difference scheme for tracer transport equation. J. Appl. Meteor. 20, 1485-1498.

Sellers, P. J., Randall, D. A., Collatz, G. J., Berry, J. A., Field, C. B., Dazlich, D. A., Zhang, C., Collelo, G. D. and Bounoua, L. 1996, A Revised land surface parameterization $(\mathrm{SiB} 2)$ for atmospheric GCMs. Part I: Model formulation. J. Clim. 9, 676-705.

Suarez, M. J., Arakawa, A. and Randall, D. A. 1983. Parameterization of the planetary boundary layer in the UCLA general circulation model: Formulation and results. Mon Wea. Rev 111, 2224-2243.

Taguchi, S. 1996. A three-dimensional model of atmospheric $\mathrm{CO}_{2}$ transport based on analyzed winds: model description and simulation results for TRANSCOM. J. Geophys. Res. 101, 15099-15109.
Tans, P. P., Fung, I. Y. and Takahashi, T. 1990. Observational constraints on the global atmospheric $\mathrm{CO}_{2}$ budget. Science 247,1431-1438.

Taylor, J. A., 1989. A stochastic Lagrangian atmospheric transport model to determine global $\mathrm{CO}_{2}$ sources and sinks - a preliminary study. Tellus 41B, 272-285

Tiedke, M., 1989. A comprehensive mass flux scheme for cumulus parameterization in large-scale models. Mon. Weather. Rev. 117, 1779-1800.

Tobler, W. 1995. Population database of the Consortium for International Earth Science Information Network (CIESIN) and the Environmental Systems Research Institute, Inc. (ESRI), through the National Center for Geographic Information and Analysis, Dept. of Geography, Univ. of California, Santa Barbara, CA. NCGIA Technical Report TR-95-6

United Nations, 1994. 1992 Energy Statistics Yearbook. United Nations Publication Sales No. E/F.94.XVII.9, Department for Economic and Social Information and Policy Analysis, Statistical Division, New York.

Weiss, W., Sittkus, A., Stockburger, H. and Sartorius, H. 1983: Large-scale atmospheric mixing derived from meridional profiles of Krypton 85. J. Geophys. Res. 88, 8574-8578.

WMO, 1995. Scientific assessment of ozone depletion: 1994. Rep. 37, Global Ozone Res, and Monit. Project, Geneva. 